\title{
El Significado de la Imaginación en la Fundamenta- ción Kantiana del Conocimiento Científico
}

\author{
"el kantismo no fué cosa'de cabeza, sino de \\ corazón; asunto de la vida entera".--NATORP. \\ ("Em. Kant y la escuela filosófica de Marbur- \\ go", trad. J. V. Viqúeira, pág. 63).
}

\section{PROLOGO}

La actitud filosófica, que es actitud de sorpresa y descubrimiento, advierte en cada dato, que se ofrece a su meditación, "un universo". Todos los hechos se convierten, ante su inquisitiva y penetrante mirada, en fecundas canteras de donde se puede extraer la más alquitarada y substantiva verdad. Misión de continuo taladro cuyo sino es desbrozar prejuicios, desplazando al mismo tiempo tenaces resistencias.

El pensamiento, al apuntar hacia lo desconocido, produce una atmósfera de tensión cada vez más estrecha, la que se quiebra cuando llega a distinguir lo inédito, engendrando, por cristalización de sus elementos esenciales, un sistema o una teoría.

¿Qué posición, en consecuencia, debe adoptar el que hurga dentro de las sutilezas de una concepción? ¿Es suficiente percatarse de su riqueza con una observación simplemente horizontal de sus alcances? ¿O, por el contrario, saldrán a la luz sus más escondidos quilates en una indagación vertical de su contenido? Sólo esta segunda posición puede hacernos recapturar algunas intuiciones geniales y evaluar sus proyecciones.

Este es el objeto del presente trabajo: Penetrar en lo vertebral de la teoría Kantiana del conocimiento científico, para poder encontrar una respuesta a la interrogante que plantea la participación de la imaginación. Y no creemos equivocarnos en nuestro intento, pues a través del análisis 
que realizamos en los cuatro capítulos siguientes: acerca de la objetividad, la imaginación, los furidamentos del conocimiento científico y la hipótesis, hemos corroborado las profundas ramificaciones que tieno dicha facultad con problemas de orden psicológico, epistemológico y metafísico, y cómo la intervención de un factor de orden irracional cambia toda la perspectiva donde se ha contemplado, séanos permitido decirlo, casi unilateralmente la filosofía de Kant.

Son tantas las consecuencias y sugerencias que afloran en el curso de este ensayo, que no juzgamos erróneo aseverar, como ya en estos últimos años se ha hecho, una revalorización de la Filosofía Crítica que rebase todo exclusivismo de escuela y la señale como punto de partida para una interpretación amplia de todas las cuestiones referentes a la vida y a la cultura.

\section{INTRODUCCION}

El análisis de una teoría filosófica, conduce a la aprehensión de sus problemas medulares. Sin embargo, hay puntos que pasan inadvertidos, zonas del pensamiento que permanecen ocultàs por su aparente opacidad, o si se fija en ellas la atención, se las conternpla, exclusivamente, dentro del carácter general de la nueva actitud.

Pero muchas veces se cae en error al explicar estas zonas oscuras del pensamiento, por elempuje que presentasel nuevo punto de vista, que nos induce a interpretarlas como rezago de anteriores prejuicios. Tal es el caso de la Imaginación en la teoría kantiana del conocimiento. Dentro del problema de la objetividad su intervención es considerada de segundo plano, afirmándose simplemente que es un modo del intelecto, un recurso, o hasta un artificio para resolver algunas interrosjantes que debido a la época no se pudieron solucionar.

Mas, si aste punto débil y oscuro de la teoría no lo admitimos como una solución, sino por el contrario como un problema, y de los más fecundos, se verá la densidad que presenta. La Imaginación entonces es el eco de cuestiones, que no son prejuicios sino símbolos que rebasan la propia teoría de Kant.

En lo que sigue, estudiaremos la Imaginación en su referencia con los problemas de la objetividad y de la fundamentación del conocimiento científico, para luego servirnos de ellos como vía indirecta e inferir su posible significado. 
Sin apartarnos de la perspectiva del conocimiento (1), penetraremos con cierta libertad en la interpretación de aquella facultad inconsciente del espíritu que ejecuta un trabajo subterráneo y silencioso.

Mirando retrospectivamente la historia de la filosofía, observamos que las especulaciones se dirigieron, ein primer lugar, al mundo real de los objetos - naturaleza. No pocos esfuerzos desplegaron los pensadores para enfocar una nueva realidad, la que les condujo al descubrimiento del hombre mismo como interrogante infinito.

Existieron, en consecuencia, cuestiones relacionadas tanto con $\in \mathrm{l}$ mundo de lo dado cuanto con el sujeto; cuestiones que motivaron teorías marcadamente unilaterales, desembocando en soluciones ya racionales, ya em. píricas. Doctrinas que, por lo general, anteladamente habían eliminado la sospecha de la existencia de otras realidades, donde los problemas del hombre y de la naturaleza surgían vinculados. Las estructuras: ciencia, arte, moral, como hechos culturales, son objetividades que se imponen por sí mismas. Y aunque la existencia de esas estructuras pudo haber. sido captada desde muy antiguo, no fué enfocada nunca en su integridad primigenia.

Kant llega a una visión integral de la correlación del sujeto con las objetividades mencionadas (ciencia, arte, moral); descubre su nexo y pro. cura aclarar en parte los fundamentos de su "darse" como hechos. Sólo una ajustada interpretación de ellos, puede llevar a una nueva concepción del sujeto y a posibilidades teóricas de valor incalculable.

Es preciso, desde luego, sometera la reflexión las cuestiones desde el punto de vista del sujeto con su realidad. Bajo tal criterio, la interpretación central de la filosofía está en los hechos culturales, que encuentran su apoyo en el espíritu, los que al ser comprendidos mediante el reconocimiento do sus fundamentos, pretenden hacer factible el genuino significado del sujeto.

Todas estas interpretaciones parece, persiguieran el propósito de indicar lo que sea la experiencia -en sentido lato-: una amalgama entre el sujeto y la realidad, sujeto y realidad que ya no se presentan como problemas antitéticos. De este modo el aporte cultural se convierte en el sustrato básico para una explicación que rebase la cultura misma, dando motivo y sentido a otros temas esenciales que moran en su transfondo.

(1) Cabe aquí observar cómo es preciso desligarse un poco de la consabida crítica tradicional, del excesivo afán erudito $y$ del frecuente cambio de intención, en lo sustancial del pensamiento, por ajustarlo a escuelas o tendencias determinadas (psicologistas, logicistas). que son posiciones epígonas $y$ parciales. 


\section{P R I M R A P A R T E}

\section{LA OB!ETIVIDAD Y I.A IMAGINACION}

\section{A P I T U L O I \\ LA OBIETIVIDAD EN EL CONOCIMIENTO}

\section{EL PUNTO DE VISTA CRITICO}

Es necesario averiguar la finalidad que persigue la actitud crítica, porque según la perspectiva con que se mire el hecho científico, ha de surgir toda una nueva concepción de la experiencia.

En primer lugar, uno de los temas medulares, es el de la posibilidad de los hechos. Pasa a un plano preferencial ya no el descubrimiento de las determinaciones de los objetos, sino la averiguación por las condiciones a que todo objeto de conocimiento debe someterse. Desde luego, el interés de la investigación se acentúa, más que en lo adjetivo, en la fundamentación del conocimiento.

En segundo lugar, urge indagar por la ley que rige la pluralidad de los objetos, para obtener su unidad. La ley, a su vez, debe incluir la posibilidad de aquello que unifica. lli Conversom

Por lo tanto en la actitud crítica, encontramos esta doble finalidad: inquirir por la posibilidad de los objetos, y por aquello que les da unidad.

¿Dónde descansa la posibilidad y la unidad? Si se indica la'causa que unifique y posibilite los hechos, ambos problemas se resolverían en uno.

En el conocimiento ¿es el obieto el único que imprime su realidad en el sujeto, o por el contrario es el sujeto el que en cierto modo transforma al objeto? ¿La espontaneidad del sujeto no puede resolver la unidad y posibilidad de los objetos? Si el hecho del conocimiento objetivamente válido (la Ciencia) encuentra su posibilidad en la unidad que impone la espontaneidad del sujeto, puede erigirse dicha espontaneidad en la clave de la objetividad y de los alcances de la Ciencia:

Queda abierto, pues, el problema de cómo actúa la espontaneidad del sujeto y dónde radica el núcleo de su validez, para con sentido crí. tico hablar de un campo teórico. 


\section{LA OBJETIVIDAD EN LA CIENCIA}

\section{I) SENTIDO DE IA FUINCIOIN EN EL CONOCIMIENTO}

La espontaneidad es la vía para percatarse del carácter funcional que supone el entendimiento, el que otorga unidad a las representaciones, porque realiza su labor mediante conceptos, que implican un poder de organización.

Los conceptos aparecen como órganos activos, que en cierto modo producen nuevas representaciones. En ellos sólo hay una alusión mediata a objetos, acudiendo a la representación. De allí que la funcicnalidad se verifique por conceptos, los que remiten las representaciones a otra más general.

Pero la conceptuación es un peldaño de la unificación representativa, porque podemos observar, de hecho, que el concepto adquse:? sentido al presentársenos en el juzgar sobre objetos, y entoncss, er. un segundo plano, el entendimiento, mediante el juzgar, refiere estos conceptos (funciones unitarias) unos a otros, ejerciendo de nuevo su pccier funcional al vincularlos por medio de conceptos más generales.

La funcionalidad judicativa, ejercida por el entendimiento, proporcicna la unidad. Pero la sencillez de este proceder, en su contribución a la unidad, tiene sentido diferente si la encaramos desde el aspecto formal, o si lo hacemos considerando el contenido. De allí que habría una génesis distinta en ambos aspectos, genética que nos revelaría la misión adecuada y peculiar de la función en el conocimiento. Formalmente (en la Lógica), las representaciones se conceptualizan poniendo entre paréntesis la forma en que se muestran o presentan, valiéndose de las representaciones que son dadas, y explicitando o explicando analíticamente lo que hay de común para extraer el concepto.

En este proceder se pone el acento en la génesis no propiamente del dato sensible que va a conceptualizarse, sino en cómo las representaciones se hacen conceptos en el acto del pensar (2).

No es problema, si la representación tiene o no valor objetivo, ya que indiferentemente puede ofrecer cualquier origen. Pero si la génesis

(2) Kant indica las operaciones que se realizan para la génesis lógica del concepto. Hace ver cómo se necesita de la Comparación, o sea la aproximación por el pensamiento de las representaciones, con relación a la unidad de la conciencia: la Reflexión, o sea el atender a cómo diversas representactones pueden ser comprendidas en una conciencia única; $y$, por último, la Abstracción de todo aquello en que se distin.juen las representaciones dadas. (Tratado de Lógica, pág. 98). 
del concepto se interesa principalmente por indagar el sentido de la unidad, en tanto unidad de un contenido nosible, se enfrenta a nosotros el problema del origen de lo que puede ser conocido. Aquí no se puede dejar de considerar que el entendimiento tiene ante sí un múltiple de la sensibilidad (a priori) que conforma el contenido.

Pero, ahondando en la génesis del múltiple, es conveniente precisar si participa del concepto como un caos, o si hay un elemenlo que por decirlo así lo agrupa, dándole un cariz unitario. Por eso es que ahora ya no es suficiente la explicilación, que no cumpliría ningún papel, sino lo que podría llamarse la "comprensión", encarnada en la síntesis.

Aparece entonces un factor coleccionante, que si reúne lo vario es en favor de la unidad conceptual, factor que desde luego se hace imprescindible. En el conocimiento, los conceptos y la funcionalidad tienen pues que mirar a un conjunto sintetizado (3).

\section{II) LA OBJETIVIDAD Y EL CONOCIMIENTO}

¿Cómo se puede pasar de un conocimiento subjetivo a un conocimiento objetivamente válido? ¿Cómo es posible la objetividad del conocimiento? Hay que inquirir tanto por las condiciones objetivas que presenta el sujeto, cuanto por las condiciones del objeto del conocimiento válido.

¿De qué sujeto hablamos al ocuparnos de un conocimiento objetivamente válido y cuál es el material con el que trabaja?

El problema del conocimiento científico queda demarcado: máxima;

a) por la conciencia que vincula todos los conceptos como unidad

b) por el contenido al que alude esta conciencia, y

c) por la síntesis que posibilita se dé un contenido a la conciencia.

\section{a) La unidad}

Asistimos con la interprelación crítica de la unidad objetiva: 1) a un reajuste más exacto del campo científico y al desmoronamiento de arcaicas teorías filosóficas que recurrían a la unidad absoluta, y 2) a la superación de las, por entonces, recientes doctrinas empíricas basadas en la asociación.

(3) "El misino entendimiento, pues, y mediante las mismas acciones por las cuales produjo en los conceptos la forma lógica de un juicio por medio de la unidad analítica, pone también por medio de la unidad sintética de lo múltiple en la intuición en general, un contenido trascendental en sus representaciones".-Crítica de la razón pura, tomo I, pág. 210. trad. Morente). 
La actitud crítica nos lleva al deslincie de todo lo que no posee la genuinidad de lo cientííico. Porque si es obvio que cualquier representación intuitiva, al transformarse en conocimiento, supone el haber sido amalgamada al pensamiento de esa propia representación, esto no basta. Es necesario una cualidad para determinar el punto posibilitante del conocimiento válido. Y la cualidad requerida, es que el sujeto sea idéntico en todo múltiple.

Es forzoso rebatir los argumentos que consideran tan sólo al pensamiento como imprescindible para verificar la unidad intuitiva, y dejan de lado la identidad del sujeto. Así, atacaríamos la continuidad de la experiencia. El secreto de la Ciencia consiste en hacer experiencia del múltiple de representaciones, ella implica relación de hechos que indiscutiblemente suponen la misma unidad en todos y nunca un recomenzar en cada uno de ellos.

De esta manera, la espontaneidad se yergue como la creadora y objetivadora de todo hecho capaz de ser experimentado. El aporte critico estriba en que la identidad del sujeto, y la continuidad del objeto, no provienen de una explicitación, de una mera y simple deducción, sino que ellas se conciben por enlace. Y aquí radica el primer paso valioso en esta nueva caracterización de la objetividad: en la identidad del sujeto y en la síntesis que él impone, descansa la singularidad de la posición epistemológica y el desvanecimiento de todo supuesto unitario absoluto.

El sujeto idéntico, "frente a un contenido plural y heterogéneo, estructura lo esencial en todo conocimiento científico, y produce la homogeneidad unitaria de "lo dado".

Pero lo más logrado en la teoría de la unidad objetiva kantiana, se percibe en el señalamiento del exacto punto de vista del conocimiento científico, al liberarlo de toda tendencia escéptica y psicologişta.

La objetividad del múltiple encuentra su apoyo en la autoconciencia, erigida como unidad máxima. Solamente por la unidad que objetiva lo vario y, a su vez, lo posibilita, el múltiple, en apariencia ajeno y aún extraño, tórnase de simple dato subjetivo en objeto. Existe, por consiguiente, una unidad sintética que reune lo múltiple, inserto en un concepto, es decir, objetivado. Unicamente en dicho proceso, avizoramos el germen de la objetividad. 
Con la anterior interpretación, se construyen los nuevos fundamentos del pensar científico, puesto que el juicio, relacionando conceptos, reúne sin lugar a dudas las representaciones en un objeto en general, mediante la unidad de la apercepción. Podemos observar entonces, cómo es la estructura judicativa, y no la psicológica, lo primordial. La unidad empírica, ha sido rebasada (4).

Para la objetividad, son indiferentes las fluctuaciones del sujeto, y la experiencia, como conjunto de representaciones, ya no es una yuxtaposición de ellas. Porque la unidad en el conocimiento científico es diferente a la que se realiza empíricamente (sentido interno). Pero a pesar de la solidez del nuevo punto de vista, no por eso dejamos de reconocer que si bien en todo el proceso de unificación se revela la importancia de lo espontáneo, y el aporte del sujeto trae un modo inédito al contemplar las cosas, la apercepción trascendental, sin embargo, muéstrase limitada, al ser el eje de toda posible dirección exclusivamente teóricaracional.

\section{b) Objeto científico (5)}

Las diversas apreciaciones sobre la contextura del objeto, no son otra cosa que las proyecciones de las numerosas tendencias filosóficas, idea listas o realistas, racionalistas o empiristas. Mas los problemas de orden gnoseológico no son los únicos que se debaten, sino además es el "objeto" el punto crucial de posibles interpretaciones metafísicas. El lleva en sí toda una problemática gnoseológica, cuya solución indudablemente tiene fuertes repercusiones en otros campos. SPor eso cabe anotar, que en la interpretación kantiana del objeto (en el campo del conocimiento!, aunque reverberan antiguas cuestiones, ella representa, al mismo tiempo,

(4) "Pero si yo investigo más exactamente: la referencia de los conocimientos dados en todo juicio y la distingo, como perteneciente al entendimiento, de la relación según leyes de la imaginación reproductiva (relacićn que tiene sólo una validez subjetiva), entonces hallo que un juicio no es otra cosa que el modo de reducir conocimientos dados a la unidad objetiva de la apercepción. Para eso está la cópula "es", en los juicios, para distinguir la untdad objetiva de representaciones dadas, de la subjetiva".- -Crítica de la razón, tomo I, págs. 256-57, trad. Morente).

(5) Como en el presente trabajo, y sobre todo en los primeros capítulos, utilizamos las ideas dadas por Kant en la deducción trascendental de su Crítica de la razón pura, es interesante anotar que hay dos fuentes: la que nos ofrece la primera edición, y la que nos ofrece la segunda. Se hace evidente en los intérpretes cle Kant la pieferencia, y hasta la exclusividad, por una u otra fuente como la verdadera.

Nosotros, en este trabajo, tomamos como fuente primorclial la sogunda edición, pero apoyándonos en muchas consideraciones dadas en la primera. 
un minucioso y profundo trabaio, donde se expone la configuración del objeto epistemológico. Sin embargo, no deja de ser verdadero que la teoría crítica sobre el objeto, trae, a su vez, nuevas interrogantes, debido a la persistencia de ciertos aspectos oscuros.

\section{1}

Kant define el objeto del conocimiento válido, como "aquello en cuyo concepto lo múltiple de una intuicićn dada es reunido", (Crítica de la razón pura. t. I, pág. 251, trad. Morente). Este objeto, que presenta una fisonomía de necesidad, no puede ser lo simplemente dado a mi aprehensión, él implica algo más. Encontrando el punto donde radica su peculiaridad, se descubre el significado y la estructura del objeto epistemológico.

Es, pues, imprescindible que se dé lo múltiple de una intuición como incluído en un concepto, para forjar un objeto. Objeto no es lo múltiple dado, sino lo múltiple comprendido en un modo general, en un con-

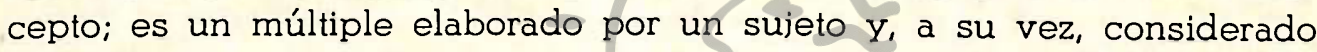
en general.

El objeto científico trae la cualidad objetiva de la unidad, siendo al mismo tiempo permanente y continuo. Existe la obligatoriedad de realizar una síntesis unitaria en la multiplicidad intuitiva; y la unidad impuesta a lo plural como una regla, es la que se propone mediante el concepto, que vendría a ser la regla unificadora.

Como el concepto "es lindispensable en el conocimiento, se le utiliza como regla. Sólo por medio de estas reglas se hace posible, el conocimiento científico. Pero, a su vez, la permanencia del objeto nos remite a la consideración de que los conocimientos deben tener entre ellos una relación, relación impuesta por el objeto al que se dirigen. Porque la misma unidad ofrecida por el objeto, es la brindada por el conocimiento de dicho objeto. Las condiciones del objeto científico, revelan también la posibilidad científica. Vale hacer presente, en último término, que la unidad del concepto está fundamentada en la unidad impuesta por el sujeto idéntico (6).

(6) "Mas como sólo nos ocupa la diversidad de nuestras representaciones, Y como la X que les corresponde (el objeto) no es nada para nosotros, puesto que debe ser alguna cosa distinta de nuestras representaciones, es claro que la unidad que constituye necesariamente el objeto no puede ser otra cosa que la unidad formal de la conciencia en la síntesis de las representaciones diversas".-(Crítica de la razón pura, 1ạ edición, t. I, pág. 267. trad. M. Fernández Núñez). 
Hasta aquí el fundamento del objeto científico. Pero ¿cómo se hace posible la intuición empírica sobre la cual se construye el objeto necesario? ¿Cómo la pluralidad de impresiones toma una cierta hornogeneidad y se concibe orgánicamente?

La pluralidad de impresiones adquiere unidad mediante una captación o aprehensión sintética, por la cual se estructura una multiplicidad caótica (7).

Así se posibilita el ienómeno. Pero la propia conformación del fenómeno presenta un problema. Si observamos el fenómeno, vernos que la multiplicidad empírica de sensaciones que lo constituye, adquiere unidad por las formas puras espacio-temporales, lo cual-parece conducirnos, desde luego, a una doble unidad impuesta a las impresiones: una unidad que proporciona la síntesis aprehensiva, y otra, que ofrece las formas puras de la sensibilidad. Más, la pretendida discrepancia en el origen de la unidad del fenómeno, se resuelve con la diferencia entre lo formal de la intuición y la intuición formal. El espacio y el tiempo son formas y a la vez intuiciones, y como intuiciones que encierran un múltiple, también ellas exigen unidad, es decir, implican una síntesis.

La doble posición del espacio y del tiempo, hace distinguir que, en su carácter formal, dan unidad a la multiplicidad de sensaciones que encierran; $y$, en su modalidad intuitiva, requieren una unidad que es suministrada por el entendimiento, valiéndose de la síntesis aprehensiva.

Las consecuencias de estáteorí, desde el terreno del objeto científico, sin duda alguna, cumplen su cometido. La antigua ruptura en la objetividad (de lo sensible y lo inteligible) sería casi un mito, puesto que el objeto científico parece sobrepasarla con su unidad. Porque como lo intelectual organiza el caos sensible, el objeto científico ensambla, de este modo, los dos puntos antagónicos.

Pero la solución en favor de la unidad (si es que se alcanza), que hace intervenir al entendimiento en la propia estructuración del dato sensible, por librarnos de un prejuicio ¿no trae la sospecha de un problema mayor? ¿Por qué es la síntesis de la aprehensión (considerada como mensajera de la unidad categorial) la que realiza la síntesis sensible? ¿Na es la síntesis de la aprehensión el efecto de la imaginación, fa-

(7) "Ante todo, advierto que por síntesis de la aprehensión entiendo la composición de lo múltiple en una intuición empírica, por la cual se hace posible la percepción, es decir, la conciencia empírica de la misma (como fenómeno)".- - (Crítica de la razón pura, t. I, página 279, trad. Morente). 
'ultad ciega e inconscienle? ¿No sospecha Kant con ella que es necesario una especie de organización espontánea en lo sensible? ¿Por qué la síntesis de la aprehensión es efecio de la imaginación? ¿Es simplemente la imaginación un modo del intelecto y una representante de él, - también es ella una facultad autónoma que nos revela, en la fundamentación de la ciencia, la existencia de un problema más profundo?

\section{c) La síntesis y su doble significado}

\section{1}

De este modo la unidad de los conceptos y el contenido que ellos encierran, nos pone en contacto con el meollo mismo del conocimiento: la síntesis.

En el proceso de objetivación del conocimiento empírico, tanto en el logro de la unidad necesaria y universal cuanto en la posibilidad del contenido y su objetivación, la síntesis ejerce un papel primordial. Lo sintético se presenta con una peculiaridad, es el factor dinámico dentro de la aparente rigidez del sujeto permanente y de la continuidad del objeto.

Pero el proceso objetivador, que Kant lo señala por una triple síntesis (8), resume toda su fuerza en la síntesis que ofrece un aspecto

(8) La explicación del proceso de la triple síntesis plantea un pıoblema. La triple síntesis es, en opinión general, la representante más señalada del racionalismo kantiano, puesto que mediante este proceso. Kant quiere someter lo sensible, como conjunto dado solo por la espontaneidad de tipo intelectual, ya que él no le asigna a la sensación ninguna espontaneidad. Por eso, debe recurrir no únicamente a la síntesis que el entendimiento produce, sino a la síntesis de tipo intelectual, pero vinculada al contenido receptivo sensible, mediante dos especies de síntesis: la síntesis imaginativa y la aprehensiva. En esta forma, el triple proceso sintético (síntesis aperceptiva, síntesis imaginativa en dos aspectos: trascendental y figurada, y síntesis aprehensiva) y el esquema solucionarían la espontaneidad que debe existir en el conjunto sensible para que se constituya como tal. Esta sería la interpretación más lógica y ajustada a la idea kantiana y a su modo de pensar. Pero si nosotros observamos que aqui aparece una fuente de conocimiento, que no es el intelecto, sino que a pesar de tener las características de la espontaneidad. Kant la denomina imaginación, podremos ir siguiendo su proceso y llegar a su significado, que quizás reforzaría el indicio de una posible interpretación más amplia de la espontaneidad y de la fundamentación de la ciencia.

La imaginación interviene en la síntesis de la aprehensión; luego, ella realiza una síntesis de doble significado; $y$, for último, organizando los conjuntos que van a formar la experiencia, es el paso forzoso e indispensable a la unidad. Pero la imaginación, forma espontánea, no es una fuente racional, porque el mismo Kant indica que es una fuente inconsciente.

Podríamos entonces, mirando el problema desde este punto de vista, preguntarnos, más allá del triple proceso sintético, por el significado de la síntesis que ante nosotros se hace 
dual, en donde se patentiza el peso significativo de la fundamentación científica. Sin duda alguna, dentro del triple proceso sintético se filtra toda una concepción del conocimiento científico $y$, por lo tanto, para comprenderlo no basia exponer la triple síntesis, sino entrever su significado en el auténtico afán oue lo anima, cuale es el de conducirnos a una interpretación más ajustada de la objetıvidad.

\section{2}

Como en el conocimiento válido se verilica una unión de lo múltiple intuitivo con el concepto puro, es justo indagar por la sintesis que directamente la ejecuta, cuya misión, notoriamente, abarca una dobla finalidad. De un lado, aparece la referencia a la conciencia objetivadora en general; y, de otro, a lo vario de la intuitividad. La síntesis fundamenta ambas referencias, y así al mismo tiempo que vincula lo múltiple a la conciencia en general, mediante los conceptos sintéticos máximos (categorías), al mismo tiempo produce la síntesis intuitiva que posibilita el contenido en el concepto mediante una representación general.

A la síntesis que refiere lo intuitivo a una conciencia en general, se la denomina Síntesis trascendental de la imaginación; y a la que se preocupa por la posibilidad de la dación intuitiva como contenido del conocimiento, se la titula síntesis figurada.

Existe pues una síntesis que considera, en primer término, la fusión de lo múltiple sensible válido a priori (síntesis figurada o speciosa). Y, en segundo término, da síntesis dirigida a da unidad máxima posibilitadora de todo conocimiento válido, que relaciona los conceptos puros a un contenido (síntesis trascendental de la imaginación).

Esta síntesis (en su doble aspecto) es el fundamento de todas las demás, fundamento de la aplicación de las funciones válidas y necesarias del entendimiento a todos los objetos intuíbles. Por medio de ella, que en general se la asigna como "síntesis de la imaginación", se puede relacionar lo múltiple con la unidad sintética trascendental y, a su vez, darle intuitividad al objeto de esa síntesis general.

Sin la anexión a una conciencia en general y sin la intuición necesaria para que se haga objetiva, no sería posible el conocimiento científico.

Se ve cómo se someten los fenómenos mediante la síntesis a reglas universales, y cómo lo fenoménico llega a tener las cualidades debidas

primordial (sintesis de la imaginación); y después de ello, desembocar en la temática de la facultad sintético-imaginativa. 
para que podamos hablar de una experiencia en géneral y de un campo científico, campo científico que está de acuerdo con la esencialidad del objeto y del sujeto.

Por eso creemos que la síntesis de la imaginación representa, no propiamente el recurso para alcanzar la objetividad, sino la necesidad que en todo conocimiento científico debe la unidad objetiva del sujeto referirse siempre a un contenido intuitivo (en esta teoría el contenido intuitivo es exclusivamente de naturaleza sensible). La síntesis de la imaginación, así concebida, puede simbolizar la exigencia de un contenido en todo conocimiento científico $y$, en último término, su limitación a lo sensible.

\section{CAPITULO II}

\section{IMAGINACION Y CONOCIMIENTO}

\section{IMAGINACION Y ENTENDIMIENTO, SINTESIS Y UNIDAD}

Es imprescindible aclarar el sentido del entendimiento y de la imaginación, como facultades que posibilitan el conocimiento. De este modo se esclarecerá cómo la espontaneidad del sujeto, que significa poder unitario y a la vez sintético, organiza con ese doble fundamento la experiencia. Una delimitación de la labor de cada facultad, puede iluminar en parte el significado de la imaginación. Aunque en algunos párrafos de la Crítica ambas farultades riparentemente se confunden, un análisis mostrará su diferencia, dandol luces sobrella capacidad del sujeto en tanto Yo o conciencia objetivadora, Y como poder productor 0 sintético.

De hecho, la imaginación surge como un poder sintético ejercitado inconscientemente (9). Representa una fuerza oscura y subterránea del espíritu, cuya misión es reunir y hacer posible todo contenido que constituye un objeto en un sentido amplio (ya como fenómeno, objeto indeterminado; ya como fenómeno objetivado, objeto determinado).

Pero si la imaginación, mediante este poder, es la autora a cuyo trabajo se debe la composición de elementos que originan un conocimien-

(9) "La sintesis en general es, como veremos más adelente, el mero efecto de la imaginación, función ciega aunque indispensable del alma, sin la cual no tendríamos conocimiento alguno, mas de la cual rara vez llegamos a ser conscientes. Pero reducir esa síntesis a conceptos, esta es una función que corresponde al entendimiento y por la cual, y sólo entonces, éste nos proporciona el conocimiento en la propia significación de esta palabra".(Crítica de la razón pura, t. I., pág. 209, trad. Morente). 
to, es también fundamento esencial en su labor, que al hacer factible un todo partícipe de su unidad. Mas, la imaginación no posee una fucrüa de reconocimiento, sólo el entendimiento es capaz de unificar y hacer consciente la síntesis en una estructura.

El acto cognoscitivo supone, pues, que la síntesis se apoya en un fundamento unitario, siendo el entendimiento el poder funcional y consciente del espíritu para unificar múltiples, sintetizados por la facultad de la imaginación. Las categorías (conceptos del entendimiento) por su funcionalismo, ejecutan la unidad y hacen consciente la síntesis en una totalidad.

Sin embargo, se puede argumentar que ciertos párrafos de la Crítica contradicen esta aseveración, y muestran al entendimiento como el único ejecutante de la síntesis.

"Pero el enlace (conjunctio) de un múltiple en general no pue-
de nunca venir a nosotros por medio de los sentidos, y no pue-
de tampoco, por lo tanto, estar contenido al mismo tiempo en
la forma pura de la intuición sensible; pues es un acto de la
espontaneidad de la facultad representativa y como esta facul-
tad debe llamarse entendimiento, a diferencia de la sensibili-
dad, resulta que todo enlace, seamos o no conscientes de él,
sea un enlace de lo múltiple de la intuición o de varios con-
ceptos, y, en el primer caso, de la intuición empírica o de la
no empírica, es una acción del entendimiento, que vamos a
designar con la denominación general de síntesis".
(Crítica de la razón pura, t. 1 , pgs. 242-43, trad. Morente).

Mas, lo que no es receptivo, sensible, se atribuye a la espontaneidad. Esta, en sentido amplio, se denomina entendimiento, meramente por oposición a lo sensible. Si se identifica la espontaneidad, como capacidad de enlace, con el entendimiento, en sentido amplio, se puede conferir a este último un poder de síntesis.

Pero en sentido restringido, si indicamos que el entendimiento, en el conocimiento, es la facultad que proporciona conceptos y con ellos unidad, la imaginación es entonces la facultad con que cuenta la espontaneidad del sujeto para realizar la síntesis, y la imaginación y el entendimiento (en sentido restringido) son los que efectúan la labor espontánea).

Además, si dentro del problema de la objetividad se le asigna al entendimiento un poder de construcción y de unidad, es porque en general los conceptos máximos (categorías) verifican dicha función, y al entendimiento, en último término, le corresponde esa doble labor. 
Sin salirnos del problema de la objetividad, es explicable la aparente contradicción mencionada, pues las categorías no significan otra cosa, respecto al entendifniento, que la influencia de éste sobre la síntesis trascendental de la imaginación, en tanto esta síntesis hace posible la objetividad, en la cual el entendimiento actúa como mensajero de la unidad permanente e idéntica del sujeto.

\section{LA IMAGINACION. SUS DOS ASPECTOS}

\section{A) SINTETIO (10)}

La fuerza imaginativa, cimentada en su raigambre sintética, aflora en todo análisis del conocimiento, ya sea a priori válido universalmente, ya sea empírico.

"La unidad de lo diverso en un sujeto, es, pues, sintética; la apercepción pura suministra un principio de la unidad sintética de lo diverso cn toda intuición posible.

Pero esta unidad siniética supone una síntesis o la encierra, y si la primera debe ser a priori, la segunda debe serlo también. La unidad trascendental de la apercepción se relaciona, pues, con la síntesis pura de la imaginación como con una condición a priori de los elementos diversos en un conocimiento. Fero la síntesis productiva de la imaginación, sólo puede tener lugar a priori, pues la reproductora descansa sobre las condiciones de la experiencia"- (Crítica de la razón pura, $1^{a}$ edición, t. I, págs. 283-84, trad. M. Fernández Núñez).

Esta labor sintética de la imaginación es preciso, desde luego, examinarla en dos fases: como productiva y como reproductiva (véase los párrafos denominados "Sentido de la imaginación productiva, A) Aspecto sintético productor", y "Sentido de la imaginación reproductiva, l) Aspecto sintético reproductor").

\section{B) REPRESENTATIVO INTUITIVO}

La imaginación posee el carácter de hacer intuíble o al menos representable en la intuición cualquier objeto, aunque no esté presente (11).

(10) Como el párrafo anterior lo dedicames exclusivamente a la lakor siniética de la imaginación. en ésto nos limitamos tan solo a indicar su participación en toda forma de cono. cimiento.

(11) "Imaginación cs la facultad de representar en la intuición un objeto aún sin que esté presente.-(Crítica de la razón pura, t. I. pág. 268, trad. Morente). 
La síntesis, expresión del poder recolector de la imaginación, se suma a una capacidad de representación intuitiva de lo reunido. Es decir, la imaginación en el conocimiento funciona sintéticamente, llevando en su seno un contenido intuitivo.

Según la calidad del conocimiento, la intuición imaginativa puedo ser originaria o a priori y derivada o a posteriori (12).

Pero la imaginación al proporcionar una intuición, no crea la ma! rialidad del objeto sensible que representa. Su síntesis, po: productivi que fuere, de ningún modo genera un contenido ajeno a la sensibilitdad. Siempre el múltiple con el que ella trabaja debe, en último térniino. s: mostrado.

El múltiple de efectos sensibles (sensaciones), es compuesto por la imaginación y extraído sólo de la facultad de sentir. Siempre el trabajo intuitivo de esta facultad es sensible, y mira como necesaria únicamente a la intuición empírica.

Es explicable entonces que la imaginación, en su empuje sintético al acompañar a la razón, rebasando los límites de la experiencia, represente siempre las ideas de un modo empírico, llegando en algunos casos a la antropomorfización.

Hasta aquí se han indicado los dos aspectos de la imaginación, aspectos que en toda visión integral de la función imaginativa deben ser distinguidos y que Kant los señaló, sino explícitamente, al menos en forma fácil de captar en su fundamentación del conocimiento teórico. La imaginación de esta manera, como forma de síntesis y fuerza que vivifica los objetos que forja, encierrá un significado auténticamente creador. Ella implica dos caracteres: una fuerza combinadora y un afán de objetivación, organiza y objetiva en sus aspectos sintético y representativo.

\section{LA IMAGINACION PRODUCTORA Y REPRODUCTORA}

En lo que sigue vamos a exponer las dos formas en que se presenta la imaginación: productora y reproductora.

La característica de la imaginación como potencia intuitivadora, es clara en la advertencla y definición dada por Kant en la Antropologia: "La imaginación (facultad imaginandis) o facultad de tener intuiciones sin la presencia del objeto es..." (pág. 56, trad. J. Gaos).

(12) "La imaginación es ya productiva, esto es una facultad de representarse originariamente el objeto (exhibitio originaria) que antecede por tanto a la experiencia, ya reproductiva o derivada (exhibitio derivativa) la cual devuelve al espíritu una intuición empírica anteriormente tenida".-(Antropología, pág. 56, trad. J. Gaos). 
Kant al explicar la génesis objetiva de todo conocimiento, hace notar (13) cómo todas las fuentes subjetivas o facultades que contribuyen al conocimiento presentan dos aspectos: 1) son empíricas en tanto se aplican a los fenómenos, y 2) son también elementos o fundamentos a priori que hacen posible el uso empírico.

La imaginación reproductiva circunscribe su actividad a la formación del conocimiento empírico, como hecho individual regido por las leyes de la asociación, y tiene un carácter psicológico. En cambio, la imaginación productiva es la colaboradora en la fundamentación del conocimiento a priori válido universalmente.

Pero sobre esta especie de clasificación kantiana de la imaginación y de su papel, caben algunas observaciones. En primer lugar, la imaginación es colaboradora del conocimiento objetivo, y como tal productiva, mejor dicho creadora y genuinamente sintética. (Acentuamos la palabra "genuina", porque en la actitud crítica el papel de la síntesis de la imaginación productiva se percibe más claramente). $Y$ en segundo lugar, la reproductiva es partícipe del conocimiento subjetivo y propia de la Psicología. La imaginación aparece como forma sintética, pero de carácter asociativo y sujeta a las fluctuaciones subjetivas, por no apoyarse en un soporte objetivo (14).

El aporte de la anterior clasificación, si lo contemplamos desde el aspecto productor, radica en la infuición adecuada y moderna que se hace de la imaginación como facultad creadora, psicológicamente considerada. Mas en el segundo aspecto (reproductor), se mantiene la interpretación psicológica propia del siglo XVIII - asociacionista.

La citada clasificación en productora y reproductora, tiene razón de ser si se postula, como Kant, el àspecto creador solamente para la primera y no así para la segunda. Pero si consideramos, psicológica y objetivamente, toda forma de la imaginación como productora, no tendría sentido dicha clasificación, porque en general todas las formas de la imaginación serían de carácter productor.

(13) Tercera sección de la ī̄ edición. (Trad. M. Fernández Núñez).

(14) Kant señala que Hume "concluye, pues, falsamente de la contingencia de lo que determinamos según la ley a la contingencia de la ley misma, y confunde el hecho de pasar del concepto de una cosa a la experiencia posible (la que tiene lugar a priori y constituye la realidad objetiva de ese concepto) con la síntesis de los objetos de la experiencia real, la cual siempre es empírica". Por esto indica Kant que Hume hace "de un principio de la afinidad, quo tiene su puesto en el entendimiento y expresa un enlace necesario, la regla de la asociación, que no se encuentra más que en la imaginación reproductora y no puede representarse más que con enlaces contingentes y no objetivos".- (Crítica de la razón pura, t. II, págs. 329-30, trad. M. Fernández Núñez). 
En párrafos precedentes, anotamos dos aspectos en la imaginación: el sintético y el representativo: y ahora, al analizar las formas de la ima ginación, distinguimos el productivo y el reproductivo. Por lo cual es justo aclarar, que no sólo al aspecto reproductivo corresponde el representativo y al productivo el sintélico. Cada una de las formas, productiva y reproductiva, presentan ambos aspectos.

\section{SENTIDO DE LA IMAGINACION PRODUCTIVA}

\section{A) ASPECTO SINTETICO PRODUCTOR (15)}

A través del aspecto productor u objetivador, se transparenia la acción determinante y espontánea del sujelo. La participación de la imaginación en el proceso objetivo, viene a subsanar, a primera visia, la polaridad existente entre la apercepción y la percepción sensible por el puente que, en cierto modo, ella construye. Mas si tras esta inierpretación. nos interesamos preferentemente por el significado de la imaginación, si no observamos solamente su carácter de forma arquiteclural, puesta exproleso para solucionar el prejuicio kantiano de la espontaneidad intelectual y la recepilvidad sensible, surgen entonces alcunas interrogantes que nos plantea su intervención en la génesis objetiva.

La percepción encuientrae cue posibilicled en da sintesis aprehensiva, $y$ al hacer posible la intuición empírica, es el germen de la propia objetividad de esa intulición.

"Pero como todo fenómeno contiene una diversidad, y por con-
siguiente existen en el espiritu diversas percepciones disemi-
nadas y aisladas en si, es preciso que haya entre ellas un enla-
ce que ellas no pueden toner en los mismos sentidos. Hay,
pues, en nosolros una facultad acilva que hace la síntesis de
esta diversidad: nosotros la denominamos imaginación, y a su
acción quo se ejerce inmediatamente en las percepciones la
llamo aprehensión". iCrítica de la razón pura, l" edición. I.
págs. 286-87, trad. M. Fernández Núnez).

(15) En estos párafoz utilizamos como fuentes la dedueción trascendenlal de las categorias en las dos ediciones. Nos parece de gran imporlancia el aporte de la primera edición: 1) la influencia en la percepción de las sinlesis apreluensiva y reproductiva, 2) la alinidad de los lenómenos. La segunda edición suministra con claridad la función da la imaginación eir relaçión con la unjdad en el papel de la sintesis trascendenlal de la imaginación y de la sínlesis ligurada. 
Si la imaginación es la que enlaza lo múltiple en la aprehensión, debemos distinguir que, por un lado, esta facultad contribuye a la composición de la percepción, porque la percepción implica síntesis y la síntesis no puede darse en los sentidos; y, por otro, la superación de la antigua creencia de los psicológos, al atribuir a la imaginación, exclusivamente, un poder reproductor, y asignär en cambio a los sentidos un empuje compositivo.

Aceptado, en primer término, el aporte de Kant, que la imaginación no puede ser meramente reproductora; quieda por discutir la segunda parte, según la cual al utilizar la imaginación en la percepción se afirma más aún el carácter racionalista de su doctrina, negándose toda especie de espontaneidad a lo sensible.

Pero si bien la imaginación, por un lado, puede representar el mensaje del entendimiento en la creación de la percepción; también por la característica con que se nos muestra, de fuerza inconsciente, podría indicar cierta espontaneidad en lo no racional.

¿No hay objetos sensibles fuera de toda conceptualización? ¿Cómo se realiza la objetivación? ¿El objeto sensible solamente se apoya en la categoría formal y no en otras estructuras? Dentro de la concepción crítica ¿no se vislumbra un intento, en la síntesis de la aprehensión (como producida por un efecto de la imaginación), de íundamentar lo sensible por una espontaneidad propia?

Creemos que Kant se encontró frente al dilema de que lo sensible, para la objetivación, se debía presentar como un todo organizado y, en consecuencia, existir ya en él algo de espontaneidad, espontaneidad que no la colocó directamente en ellentendimiento sino en un representante de él: la Imaginación, la cual no poseía las mismas características, dejando indudablemente con su presencia la sospecha del mencionado problema.

\section{2}

La reproducción de los dalos es un factor primario para que alcancen coinsistencia objetiva, y tiene lugar fundamentalmente por la contribución de lo imaginativo, condicionante de la afinidad entre los elementos aprehendidos. La cualidad imaginativa de reproducir representaciones, es esencial para alcanzar la identidad de los fenómenos como objetos.

En el juego reproductivo presenciamos, por decirlo así, el traslado del centro de gravedad de lo circunstancial a lo válido en general, sin cuyo paso en favor de la objetividad de la representación, se perdería 
la continuidad de la experiencia y la conlinuidad tambien do los propios objetos.

La reproducción de los ferómenos no debe descansar en la ley ase ciativa, la determina una ley de aínidad. Da otro modo. sólo exictirian fenómenos aislados y no Ciencia.

En dicho proceder apreciamos una contribución inestimable para el conocimiento del objeto, porque, sin rodeo alguno, es exacta la inlluencia de la imaginación en le identidad y génesis dsl tenómeno. Esla facultad es, bajo tal punto de vista, la que a lravés do todas las percepciones que poseamos de un cbjeto, usa de la reprodusción. para infundirle mayor objetividad. De esta manera, la imaginación juega el papel no de fantasear suponiendo partes, sino por el contrario suponiendo lo que resta de la cosa pero objetivándolo.

Hemos contemplado el trabajo de la imaginación productiva en el proceso objetivo, tanto en la percepción cuanto en la esiructuración del objelo; se nos han revelado aspectos inelabies en su relición con el co. nocimiento científico. Dichos aspectos coinciden con la apreciación mo derna de la imaginación, que le asigna un sarócter creador y activo, sin por ello cumplir al papel caprishoso de forjar representaciones arbitrarias, puesto que, a pesar de su empuje creador, zolabora en la formazión de los objetos, realizando un papel de intérprete, al elaborar el dato subje. tivo como conjunto objetivo liberado de fe individual, por existir en esta facultad un poder de construeción orgánjica y no de simple aglomeración.

\section{B) ASPECTO REPRESENTATIVO PRODUCTOR}

Afán esencial en la labor imaginativa, es brindar intuiciones, imáge. nos do lo que reune. No existe sintesis, por amplia $y$ general que parez. ca, quo no encierre un contenido. La imaginación siempre es signo de intuición.

En el conocimiento científico este trabajo lo realiza la imaginación figurada o speciosa, configuradora e intuitivadora. Del juego de dicha forma imaçinativa surge el esquema, y más allá de él algunas cuestiones sobre el conocimiento científico y sus conceptos.

\section{I}

Ante todo es preciso discriminer ol papel del conlenido intuitivo (representación) en el conocimiento a priori. La presoncia de la represen- 
tación en el conocimiento a posierio:i, no exige mayor justificativo, puesto que lo encuentra en la cosa misma, que afecta la sensibilidad y que es congruente con aquélla. Pero la presencia de la representación a priori sí plantea una interrogante: la de saber qué misión desempeña frente al concepto con el que aparece. Kant utiliza casi un mecanismo, una construcción de un proceso, para elevar la representación a calidad de contenido necesario en el conocimiento a priori.

El esquema, como representación que hermana el propio contenido intuitivo sensible con el concepto intelectual, en cierto modo heterogéneo a él, es el que nos suministraría la solución, o por lo menos seria el paso forzoso para la solución de lo que significa la representación que debe incluir todo concepto a priori capaz de convertirse en conocimiento. Pero si bien el esquema es algo forzado, pues su meta, sin lugar a duda, consiste en hacer que el concepto sea por lo menos congruente con alguna posible imagen sensible; a pesar de ello, el esquema no pretende estrictamente darnos una imagen que encaje con el concepto, sino indicar la existencia de un procedimiento necesario por el que se engendra una posible representación a priori, sin cuyo procedimiento no se obtiene un contenido de tal naturaleza.

Además, si miramos por sobre la propia construcción del esquema, y nos apoyamos en su sentido (en el indicarnos la posibilidad de una representación a priori), podemos averiguar cómo el esquema, al parecer un tanto forzado, no es sino el símbolo de un nuevo problema.

La síntesis figurada, síntesis configuradora a priori, y el esquema, son productos de la imağinación Están facultad al poseer la capacidad de hacer intuitivo todo lo que sintetiza, valiéndose de cualquier procedimiento sintético, implica siempre el factor intuitivo donde ella intervenga.

La imaginación anuncia la posibilidad del contenido en toda síntesis a priori. ¿Su inclusión no expresa que para que una síntesis sea síntesis cognoscitiva (a priori o a posteriori) debe suponer algún contenido? ¿No significa la necesidad, en tocio conocimiento a priori o a posteriori, de tener un contenido ajustado a la posibilidad cognoscitiva humana y no un contenido creado exprofeso? ¿No sugiere la necesidad de un contenido y la calidad de éste?

Indudablemente, fuera de dicha intención, si tratamos desde el punto de vista epistemológico el esquema, como función necesaria para la cbjetividad, se hace notorio el artificio del esquematismo, si su misión es simplemente la de unir lo sensible con lo inteligible para que alcance una contextura objetiva. 
En el aspecto psicológico, el signiticado del esquema es un aporto para interpretar el papel de la imaginación como participante del cono cimiento cientííico, haciendo uso de conceptos.

Si tenemos en cuenta que a esta facultad siempre se la ha conside. rado como la forjadora de imágenes y exacta reproductora de las representaciones, reconocemos también que en la aclualidad ella no tiene co. mo fin esencial formar imágenes, sino que además ejecuta una tareı creadora. El sentido que imprime la imaginación al trabajar generando esquemas es, primordialmente, originar una síntesis, luego la imagen, la cual en el concepto ya no es concreta y plena.

Tal proceder se trasluce en la Ciencia, donde se actúa con concep. tos, y la imagen aparece un tanto diluída, perdiendo a primera vista su empuje. Históricamente, ha sido éste uno de los motivos para negar la participación de la imaginación en el campo científico. Pero, en nuestro: días, se ha demostrado que, por el contrario, si se observa en la obietivación una especie de debilitamiento de la imagen, la imaginación jol ello no pierde su carácter inventivo y generador, puesto que las realidades y objetivaciones a que nos dirigimos, cada vez que generalizamos (conceptos), son al contrario realidades más ricas, ya no por la cantidad que representan sino por su cualidad de significación, al abrazar uru realidad más plena. Así, la imagen de tipo abstraclo puede erigirse en fuente primigenia, que utilizala imaginación para hacer ciencia e iruponer la unidad, transformándose en base que dé lugar a un gran emp. je de organización unitaria.

La inclusión del esquema, que propiamente no es una imagen $€ n$ concreto sino la posibilidad de una imagen, que más bien tiene caracte. res generales abstractos, nos hace ver cómo con los esquemas se obtie ne generalidades más amplias y ricas, generalidades que a pesar de poseer menos fuerza en cuanto a representaciones intuitivas, revelar uil ímpetu constructivo y organizador de la imaginación en la constituc:ón de la Ciencia.

\section{SENTIDO DE LA IMAGINACION REPRODUCTORA. ASPECTO SINTETICO. ASPECTO REPRESENTATIVO}

La imaginación reproductora, de carácter empírico, es facultad sintética en el sentido de evocación de lo dado; y facultad representativa, en el de proporcionar imágenes de los objetos. A diferencia de la pro. 
ductora, en su aspecto sintético no crea sino reproduce (evoca). Y en su aspacto representativo, ya no es índice de la posibilidad de una imagen, si .o generadora de la propia imagen.

1.l poder de evocación de la imaginación reproductiva se hace patente en esta frase: "Pero es claro que esta percepción de lo diverso no produciría por sí misma imagen ni conjunto de impresiones sino hubiera alli un principio subjetivo capaz de evocar una percepción de la cual parte el espíritu para pasar a otra, después a la siguiente, y así representarse toda la serie de estas percepciones; quiero decir, un poder completo de la imaginación, poder o facultad siempre empírico".--(Crítica de la razón pura, $1^{\alpha}$ edición, t. I, págs. 287-88, trad. M. Fernández Núñez).

El principio empírico que rige el proceso evocador es la asociación de representaciones, y mediante él se reconstruye la imagen de algo percibido anteriormente. En la imaginación reproductiva, sólo se pone el acento en el carácter evocador; en ella no hay propiamente creación sino recurso, memoria o copia. En este sentido se conserva aún el prejuicio de afirmar que la imaginación, al jugar un papel empírico, no crea sino que evoca. Actualmente se ha demostrado que la imaginación, al reconstruir, realiza creación y que en ningún momento es pasiva.

\section{"Jorge Pucchelli Converso»}

El papel representativo de la imaginación empírica es concebir imágenes de los objetos representados, es decir, mostrar un objeto en su particularidad al evocar su figura. Por medio de una especie de transcripción del objeto dado, la imaginación tiene por finalidad una intuición única.

\section{¿LA IMAGINACION FACULTAD MIXTA?}

La imaginación en la teoría kantiana, muestra un lado intelectual y otro sensible. Esta concepción nos llevaría a considerar: 19) el carácter mixto de la imaginación, y $2^{\text {9) }}$ la necesidad del dato sensible, elaborado intelectualmente para hacer labor científica. Ambas posiciones parecen explicables desde el punto de vista del criticismo. 
El primer aspecto (16) se justifica históricamente. El auge do la psicolcgía de las facultades, su denominación y división en facultades suporiores e inferiores, intelectuales y empíricas, los expresa Kant en varios párrafos de la Crítica. Y es que, como señala Otto Klem, la psicología de las facultades, existente ciesde Aristóteles, es remozada y persiste en la filosofía de Wolf (17).

Hasta Kant llega la precedente tendencia interpretativa de lo psicológico, aunque él utiliza el juego de las facultades desde el punto de vista del conocimiento. Lo que restaría preguntar entonces, es por el segundo aspecto, es decir, no ya por el carácter mixto de la imaginación, sino ¿por qué ella posee mayor fuerza en la fundamentación kantiana del conocimiento?

Nos parece que la fuerza que cobra la inclusión de la imaginación es, ante todo, simbólica, y podría ser una muestra de la perspicacia con que vió e interpretó Kant el problema del conocimiento.

Porque si el conocimiento científico, se concibe como colaboración de los puntos en cierto modo irreductibles de la sensibilidad y el entendimiento, nosotros entendemos su colabcraoión en el conocimiento y el que el sujeto sea capaz de objetivar lo sensible, sólo porque posee el poder de unir y referir ambas condiciones en un producto que es el conocimiento mismo. La imaginación poseería ese poder y se constituiría en la facultad necesaria que pone en contacto y fusiona, en un complejo, lo que es la verdad del conocimiento (18).

(16) "Nhora bien, la que encadena do múltiple de la intuición sensible es la imag̣inación. que depende del entendimiento por la unidad de su sintesis intelectual y depende de la sensibilidad por la multiplicidad de la aprehensión".-(Crítica de la razón pura, t. I, pág. 284, trad. Morente).

(17) Cristián Wolf, el primero que empleó el término "facultad". "hizo de las facultades, primero consideradas como posibilidades de los hechos anímicos, atributos del alma; llamólas primeramente nudae agendi posibilitates, concretándolas luego inás en disposiciones naturales, de manera que su relación con el alma asemejábase a la de los órganos con el cuerpo".-(Historia de la psicología, por O. Klernm, pág. 59, trad. S. Rubiano).

(18) "Imaginación es la facultad de representar en la intuición un objeto aún sin que esté presente. Mas como toda nuestra intuición es sensible, pertenece la imaginación a la sensibilidad, por la condición subjetiva bajo la cual tan sólo puede ella dar a los conceptos puros del entendimiento una intuición correspondiente; pero, sin embargo, en cuanto que su sintesis es un ejercicio de la espontaneidad, la cual es determinante y no, como el sentido. meramente determinable y puede por lo tanto determinar el sentido, según su forma, conforme a la unidad de la apercepción, es la imaginación en este respecto una facultad de determinar a priori la sensibilidad, y sus síntesis de las intuiciones, conforme a las categorías, debe ser la síntesis trascendental de la imaginación. la cual es un efecto del entendimiento en la sensibilidad y la primera aplicación del mismo (al mismo tiempo fundamento de todas 


\section{LA IMAGINACION FACULTAD CIEGA DEL ALMA}

Una de las características de lo sensible, en la filosofía crítica, es lo caótico, ciego, carente de unidad. Lo que podría conducirnos a aseverar que la imaginacion, como facultad ciega, es fundamentalmente sensible.

Pero en la fundamentación del conocimiento científico, ella aparece como una actividad espontánea y, por lo tanto implica algo más sobre 10 sensible.

De allí, que ser lauultad ciega del alma expresa que la imaginación no es una fuerza auténticamente sensible ni tampoco intelectual, sino una fuerza que nos atrevemos a denominar irracional.

¿Qué misión ejercería la imaginación como mensajera de una fuerza irracional? ¿Cómo podríamos entender lo irracional? Lo racional se oirece como lo que da unidad y tiende hacia la unidad máxima; también como un factor opuesto a lo sensible, pues posee espontaneidad. Lo sensible, en cambio, representa a la receptividad y a la pluralidad.

¿Lo irracional, por el hecho de serlo,quedaría ipso facto como lo no racional y por ser lo no racional incluído en lo meramente sensible? ¿Lo irracional sería de todos modos carente de espontaneidad y no contendría dentro de él un telos que le conferiría en cierto modo unidad?

Si se continúa haciendo esta problemática nunca resolveríamos la cuestión, puesto que parece que el problema de lo irracional (desde el punto de vista de la facultad de la imaginación, en da posición teórica) nos lleva a la consideración de no poder decir que se identifique con uno u otro aspecto, ya que no se ajusta a lo racional, ni absolutamente es congruente con lo sensible. Más bien ¿no sería un principio (si así puede llamársele) que va más allá de ambos, aunque supone algunos de dichos conceptos en su trama? En este sentido ¿lo irracional representaría lo vital?, o ¿podríamos decir que la imaginación nos conduce al problema más profundo de tratar o invitarnos a tratar el problema de lo irracional en Kant?

Con una interpretación de la imaginación como fuente irracional, llegaríamos a constatar un nuevo panorama en el problema del conocimiento científico en Kant, no ya desde un cerrado punto de vista racionalista.

las demás) a objetos de la intuición posible para nosotros".-(Crítica de la razón pura, t. I, págs. 268-69, trad. Morente). 
SEGU N D A PARTE

\title{
LOS FUNDAMENTOS DE LA CIENCIA Y LA HIPOTESIS
}

\author{
C A P I T U L O III
}

\section{LEYES OBJETIVAS E IMAGINACION}

\section{Introducción}

Por una observación atenta de los fundamentos concernientes a los fenómenos y a sus relaciones, podremos acercarnos a las raíces mismas del campo teórico y reconocer las leyes que rigen el dominio científico, leyes que proporcionan una concepción no solamente del conocimiento sino de la propia realidad. En lales normas parece desvanecerse el aliento impetuoso e irracional del espíritu, y la presión ejercida por el entendimiento indicar una zona inconmovible. La labor crítica de legislación a pesar de destruir todo prejuicio metafísico concebido en simples conceptos, hace hermética la realidad y nos pone al borde de la capacidad y alcances cognoscitivos.

Pero en la mencionada labor de codificación se debe aprehender qué ideas substantivas las sostienen y cómo de su análisis se precipita un llamado hacia una nueva interpretación de la realidad, que emerge de la única zona asequible al conocimiento: la fenoménica, cuya presencia no es una muestra de algo trunco sino aliento de proyecciones infinitas, concebidas desde otro punto de vista.

NOTA.-Antes de iniciar la tercera parte, hay que anotar que se van a exponer los principios de toda experiencia científica, sin particularizar cuáles fundamentan a una u otra ciencia, cuáles son los ejes de la matemática o los de la ciencia de la naturaleza, sino que se enfoca la cuestión como una fundamentación en general del hecho científico. Se comprende que esta fundamentación esté restringida casi a las ciencias naturales, puesto que otros problemas, sobre todo el de las ciencias biológicas por ejemplo, Kant los trata más bien en la Crítica del juicio con su interpretación de la teleología.

Por eso es que aquí pretendemos hacer resaltar el primordial punto de vista de estas leyes, o sea el de querer fundamentar el objeto fenoménico, como única posibilidad científica, y los puntos determinantes para hablar de experiencia, sea cuales fueren las leyes que en las diferentes ciencias: matemáticas, biológicas, naturales, etc., se dieran. 


\section{FUNDAMENTOS DE LA CIENCIA. LA INTUITIVIDAD (19)}

El modo más peculiar de entrentarnos en forma inmediata al objeto, es hacerlo intuitivamente (20).

Para la captacion intuitiva de un objeto, captación indispensable en ¿ul conocimienlo ¿qué condiciones se ofrecen? y ¿en que forma aparece el objeto bajo esas condiciones?

La vía de la intuitivación es la sensibilidad, por la cual hallamos un objeto que es el fenómeno (21). Pero en el análisis del propio fenomeno es donde se va a manilestar uno de los tundamentos necesarios del objeto del conocimiento. Si el fenómeno es en parte sensación y en cierto modo ordenación, casi unidad en un todo, es en consecuencia algo sujeto a condiciones que lo posibilitan como totalidad sensible. De allí que la intuición del fenómeno, nos descubre la condición de la regularıdiad. La temporo-espacialidad se convierte, de esta manera, en el punto del examen para una concepción objetiva y universalmente válida de la realidad.

Las intuiciones puras (espacio-tiempo) sólo pueden darse en tanto posibilidad de la zona sensorial, que constituye la materia del fenómeno. La intuitividad pura, como condicionante de la empírica, es a su vez el primer peldaño para una concepción objetiva. El espacio y el tiempo representan la necesidad absoluta en nuestra sensibilidad, aunque las sensaciones dadas varíen y sean múltiples.

Pero si la temporo-espacialidad hace homogéneo al fenómeno, éste conscientemente aparece como un agregado de partes afines, y siempre así como agregado. Sus elementos deben reunirsecen una intuición para producir un fenómeno. A la acción unitaria en un agregado homogéneo, Kant la denomina Magnitud. Allí descansa el supuesto de toda intuición (magnitud extensiva), surgiendo entonces la ley objetiva de los fenómenos al afirmarse que son siempre una totalidad de elementos (22).

(19) El criterio de Kant sobre la intuitividad se restringe a lo sensible. No considera en el conocimiento la intuición intelectual, tenida en cuenta posteriormente por la escuela fe. nomenológica. (Aquí nos limitaremos al estudio de la intuitividad en Kant).

(20) "Sean cualesquiera el modo y los medios con que un conocimiento se refiera a sus objetos, la referencia inmediata - que todo pensar busca como medio- se llama intuición". -(Crítica de la razón pura, t. I. pág. 117, trad. Morente).

(21) "Aquella intuición que se refiere al objeto por medio de la sensación, llámase empírica. El objeto indeterminado de una intuición empírica, llámase fenómeno".-(Crítica de la razón pura, t. I, pág. 118, trad. Morente)

(22) Todos los fenómenos son pues ya intuídos como unos agregados (muchedumbre de partes dadas anteriormente), lo cual no ocurre en toda especie de magnitudes sino sólo en las 
De este modo la intuitividad es base para la homogeneización de las partes en un objeto. $Y$ el objeto es uná totalidad plural, que nunca se puede concebir como algo simple. Sin embargo, se podría aseverar que el pluralismo de elementos significa una heterogeneidad dentro del mismo todo y, por lo tanto, un caos. Lo cual es erróneo, puesto que cambia la intención de la ley objetiva, que sólo se interesa por la idea de que toda cosa conocida (fenómeno) es un dato complejo.

Pero es tiempo ya de preguntarnos, si la idea del pluralismo homogéneo que rige a todo objeto no nos conduce a la vieja doctrina racionalista y cuantitativa de la realidad, que viene desde Galileo y se acentúa en Descartes.

Indudablemente se percibe una influencia, mas no por ello admitimos sea únicamente un rebrote de la concepción racionalista, sino un intento de mostrar, mediante la cuantificación, la infinitud plural con que se da algo en el conocimiento, y cómo todo objeto constituye un problema en cierto modo infinito y continuo (homogéneo).

\section{LA REALIDAD Y LO CUANTITATIVO (ANTIGUO CRITERIO)}

La realidad del objeto no puede resolverse en una cuantificación, los objetos no son simples agregados de partes, la diferencia y peculiaridad de cada uno no se concibe por la mayor o menor presencia de elementos. La realidad se presenta como algo más complejo, indica alguna cuantificación, o sea la presencia de un agregado; pero se patentiza además por la résistencia que ofrece a nuestra sensibilidad el carácter cualitativo. Es decir, que la sensación y el dato empírico son también índices de la realidad. De allí que ésta se dé más o menos plena en un conjunto integrado por la misma cantidad de elementos, y la plenitud del objeto descanse exclusivamente en el dato cualitativo.

La realidad, en consecuencia, no se ofrece como una matematización numérica de los objetos y de sus partes, sino que implica presencia de datos empíricos. En ella los objetos son unidades plurales, cuya mayor o menor realidad radica en el carácter cualitativo con que nos impresione.

Antiguamente, sin embargo, se resolvía el ser en una mera cuantificación, justificándose de este modo una serie de prejuicios, que tienen mucho que decir en contra de la propia constitución del objeto científico.

que son aprehendidas y representadas por nosotros extensivamente".--(Crítica de la razón pura, t. II, pág. 21, trad. Morente). 


\section{LA SENSACION Y LA OBJETIVIDAD}

La sensación (23) es la parte material de un fenómeno. Las sensaciones en su multiplicidad y variedad son el sustrato bajo el cual se construye la realidad de un algo independiente, que captamos mediante nuestra receptividad. Por lo tanto, tratar la sensación como el efecto de ese algo que nos afecta, y ser ese efecto de carácter subjetivo, no quiere decir que, por medio de la sensación, se forje el material del fenómeno, sino que éste al aprehenderlo se da como un todo de sensaciones.

La objetividad a priori mostrada por las cosas, en tanto intuiciones puras, contrasta con la realidad múltiple subjetiva ofrecida por la sensación; pero a pesar de ello, la sensación es la única mensajera de la posibilidad de mostración material de la realidad empírica. De aquí que la sensación ejercite también, en cierto sentido, su necesidad, siendo imprescindible para la conformación del fenómeno un cierto grado de afección sensorial (24).

La multiplicidad de sensaciones hace palpable la existencia de algo real, en unidad y no en parte, al verificarse en un mismo instante el enlace compositivo de lo múltiple empírico.

Desde esta perspectiva se aprecia la magnitud por comparación, pues lo cualitativo, en el conocimiento, está en función de lo puramente formal, exento de datos empíricos, La sensación muestra un contenido de mayor o menor intensidad, indicando la aprehensión lo cualitativo del material sensible captado.

De lo expuesto, obtenemos un criterio cobjetivo: la necesidad de lo cualitativo para toda objetividad que trate de conocimiento y no de simple invención. Probándose por la resistencia, la presencia de algo que está más allá de nuestra subjetividad. La reàlidad fenoménica no es, en sentido estricto, creada, sino elaborada (en cierto modo creada). En este punto radica el problema crucial del conocimiento científico, la famosa encrucijada de las concepciones realista e idealista. En la solución crítica, anteriormente esbozada, distinguimos una posición intermedia y no un acentuado idealismo, proyectándose la realidad de esta manera como una resistencia intensivo-unitaria que nos afecta.

(23) "El efecto de un objeto sobre la capacidad de representación, en cuanto somos afectados por él, es sensación". Y lo que se enfrenta al sujeto afectándolo es un algo que da lugar al fenómeno.-(Crítica de la razón pura, t. I, pág. 118, trad. Morente).

(24) Kant desecha la idea seguida por la escuela leibnizowolfiana, en la que la sensación nos mostraba al objeto en sí, pero en forma caótica y confusa; y el entendimiento, al mis. mo objeto en sí pero de manera clara y precisa. 


\section{SIGNIFICACION DE LA CONTINUIDAD Y EL SENTIDO DE INFINITTO}

La concepción del fenómeno tiene proyecciones insospechadas. Como base objetiva en la que se apoya todo conocimiento y como objeto único, es mostración precisa de lo que entendemos por realidad.

No podemos hablar del ser del fenómeno, de su conformación estructural, sin reconocer que constituye una pluralidad intuitiva homogénea capaz de afectarnos. Estos caracteres y su participación conjunta, encarnan la realidad como un todo de infinita posibilidad de presentaciones. La experiencia es inagotable en sus manifestaciones, en cada aspecto hay no sólo un pluralismo de elementos que colaboran, sino una multitud de posibilidades. Esta enorme realidad es, a la vez que homogénea, continua; no se agota, ni se reconstruye por simple creación. Es toda una productividad que se desenvuelve, donde el espíritu elabora y unifica. Según lo cual se observa, en la experiencia científica, un infinito de posibilidades, enmarcadas por la continuidad del objeto y la identidad del sujeto.

Cada trozo de la realidad, cada parte de ella, es una pluralidad continua de elementos y modalidades, constituyendo el ser un infinito posible. (Se supone que aquí se habla de continuidad, siempre de acuerdo y regida por las condiciones cuantitativa y cualitativas de la experiencia).

Vemos, pues, lo ligados que están los conceptos de continuidad y de infinito. Cabe añadir aquí lo que Walter Kinkel ha expresado refiriéndose a Leibnitz: que el principio de continuidad se origina en lo infinito, y conjuntamente con laccontinuidad aparece la idea de identidad. Son así continuidad, infinitud e identidad, puntos básicos de toda experiencia objetiva.

\section{LA CUANTITATIVO Y CUALITATIVO Y LA OBJETIVIDAD DEL CONOCIMIENTO}

Para que se conforme un fenómeno y su estructura adquiera unidad, ha de apoyarse en bases objetivas que transformen el múltiple empírico en conocimiento. La cantidad y cualidad se erigen como leyes objetivas que regulan la aprehensión o captación consciente del fenómeno. Estas bases son las formas unitarias a que se somete la cosa: ser un agregado y estar formado por algo que nos afecta.

La unidad objetiva que impone el sujeto, ejercitada mediante su espontaneidad, se hace factible aun en la aprehensión y constitución del objeto como fenómeno, por la cantidad y cualidad, y, por ello, la aprehensión psicológica, subjetiva y varia, debe someterse a ciertas leyes 
objetivas posibilitantes. El fenómeno mudable por naturaleza puede, como tal, formar e integrar la unidad objetiva científica, al ser lo cualitativo y cuantitativo supuestos de todo objeto necesario.

\section{I.A POSIBILIDAD DE LA EXPERIENCIA CIENTIFICA. SUS SUPUESTOS FUNDAMENTALES}

El conocimiento humano tiene como soporte único la multiplicidad fenoménica. En los párrafos precedentes, fueron expuestos e interpretados los fundamentos objetivos del fenómeno como entidad aislada. Pero, además, es necesario encontrar la posibilidad fenoménica en tanto conjunto y conformando la experiencia científica, lo cual es materia de los párrafos que siguen.

\section{1}

Indudablemente el sujeto alcanza a transformar la realidad $y$, en cierto sentido, a construirla, al mostrarnos un campo organizado bajo supuestos y condiciones tan pertinentes al objeto válido como al conocimiento también válido de ese objeto. En los diversos fenómenos se distinguen, como notas fundamentales, una continuidad y un nexo interno. Ellos pueblan la experiencia formando un conjunto, donde aparecen relacionados entre sí. Existe por lo tanto un supuesto que hace factible toda relación; y éste no puede ser otro que el supuesto de la permanencia del ser.

Pero este sustrató permanente, a que apunta loda realidad cambian. te, no es aquel absoluto al que nosotros no llegamos, sino el permanente de lo intuitivo. Es una sustancia relativa (a la intuitividad). Se habla de lo permanente en el sentido de lo intuitivamente aprehendido por $\mathrm{mi}$ sensibilidad, y la sustancia aparece libre de toda absolutez, erigióndose un permanente-relativo al conocimiento.

Históricamente, antes de Kant lo sustancial habitaba la zona de lo dado en sí, de lo por naturaleza exento de cualidades. Posteriormente se evolucionó hacia la idea de que si lo sustancial era inabordable, sus determinaciones en cambio podían ser asequibles al conocimiento. $Y$, años más tarde, se eliminó a lo sustancial del campo del conocimiento, puesto que ni la propia apariencia servía de medio para abordar lo permanente.

Fué entonces cuando Kant trajo, por decirlo así, a la sustancia al terreno de lo cognoscitivo, proponiéndola como supuesto científico, dándole el carácter de permanente $y$, cosa genial, relativizando su esencia- 
lidad en función de lo cognoscitivo. Este sustrato se erige así en signo de objetividad científica, al postular y realizar la unidad fenoménica necesaria.

La substantividad, entendida de esta manera, no sólo es el eje de la referencia de toda relación entre los fenómenos, sino de toda modificación en ellos $\mathrm{y}$, por lo tanto, de toda determinación. Porque si nos fijamos bien, las relaciones entre los fenómenos y sus modificaciones, son formas varias tanto en el conjunto como en la individualidad de lo primario y substantivo que ellos suponen.

Sólo bajo este fundamento, el sujeto puede representarse un conjunto como continuo en la relación de fenómenos, y sólo así también las modificaciones pueden ser consideradas como determinaciones y no como circunstancias.

¿Se podría hacer de la experiencia una experiencia objetiva, sino se concibe aquella unidad permanente frente al sujeto? De ningún modo, pues hay que considerar que los fenómenos se nos dan en el tiempo, y toda relación y modificación supone la relación con el tiempo y con algo que permanece en él. Esta permanencia dentro de todo tiempo, este sustrato, es la substancia.

\section{2}

Ahora el problema consiste en que la objetividad del conocimiento responda al ideal de toda ciencia: que los hechos y sus variantes presenten unidad. Por eso, la dación de los diferentes aspectos del ser de las cosas, no debe realizarse arbitrariamente $Y$ ha de responder al carácter de experiencia válida.

La variabilidad de la substancia relativa muestra una serie de sucesos, que son los únicos capaces de ser enunciados científicamente. En la experiencia teórica se habla de hechos, de modificaciones y en cierto sentido de cambios, solamente de lo que permanece en todo conocimiento, no de modificaciones de lo substantivo mismo sino más bien de sus determinaciones presentativas.

El campo científico es pues un conjunto de hechos, de lo substancial -así concebido. La objetividad de ellos y su variabilidad, es lo que se debe explicar al fundamentar una ciencia. ¿Cómo se presentan objetivamente los hechos? En la sucesión de los fenómenos no puede reinar la subjetividad y la arbitrariedad, pues se rompería la unidad de la experiencla.

¿En qué consiste la relación objetiva? Consiste en no detenerse a mirar la sucesión de los hechos que empíricamente se suceden, sino 
en captar tras la representación, la relación objetiva que fundamenta el suceder.

En el enlace objetivo, descubrimos que una representación, si sucede a otra según el objeto, debe incluir en una de ellas algo que la otra contuvo, o sea la relación entre ambas y la equiparidad de las condiciones que las fundamentan. Esta relación, siguiendo un orden objetivo, es la relación causal u orden causal (causa-efecto). Así se produce cierta objetividad en las modificaciones de los fenómenos. Se puede entonces hablar de cambios en la experiencia manteniendo la objetividad, al convertirse la relación causal en relación objetiva.

Si consideramos, pues, la experiencia con sus múltiples y variados hechos; si condición de ella es el supuesto de algo subyacente que posibilita toda sucesión como alteración; es también condición indispensable del campo epistemológico que la alteración se dé según un modo objetivo, válido para toda determinación y suceso.

Por lo anterior, hemos visto cómo el principio causal se refiere únicamente a lo fenoménico, su campo peculiar es el científico y no otro. $\mathrm{Ni}$ la causalidad considerada como mero concepto (racionalmente), ni como recurso metafísico.

Y aún dentro del terreno científico, contemplamos a la causalidad, desde la actitud crítica, desligada da toda intención psicologista. Mas esta dilucidación del papel causal, no lleva tampoco al extremo de un naturalismo causalista, puesto que Kant señala leyes teleológicas, contraponiendo la libertad a lo causal. En consecuencia, dicha interpretación causal no llega a tal extremo, y rechazalla concepción de Spinoza, de un acentuado causalismo naturalista.

\section{3}

La experiencia supone un conjunto de fenómenos independientes, pero que al mismo tiempo tienen una interinfluencia recíproca. La reciprocidad entre los fenómenos es necesaria para concebir la unidad en el conjunto, conjunto en el cual no hay meatos; la reciprocidad colabora para que no sea trunca la experiencia, constituyendo su más auténtico apoyo.

La importancia de lo precedente se acentúa al darnos cuenta que, por la comunidad de los fenómenos, por su necesaria reciprocidad, se llega a corroborar su existencia como algo, si bien distinto del sujeto, que guarda una íntima relación con él. El sujeto, por decirlo así, se siente partícipe del conjunto $y$, por contraposición con lo que se le opone, comprueba su colaboración independiente y unitaria en él. 
Así, la comunidad nos revela la existencia de los otros fenómenos, y también la de nosotros como participando de la experiencia y constituyendo el contenido que forma el territorio de toda ciencia. Se engendra de esta manera el campo teórico como una posibilidad infinita del hombre, ceñido a ciertas normas epistemológicas.

\section{LA IMAGINACION Y LA CIENCIA}

Al delimitar los puntos unitarios de la experiencia, se puede ver que esta unidad se realiza mediante un trabajo sublerráneo de síntesis. Y la síntesis, que implica la espontaneidad organizadora del sujeto y a su vez la capacidad representativa e intuitiva, es el factor al cual se debe todo ese experimento que llamamos conocimiento científico. El trabajo secreto de la imaginación trascendental (por sus síntesis y representaciones intuitivas) es el trabajo indispensable para objetivar lo fenoménico.

La imaginación ejecuta un proceso sintético en tanto tratamos de las bases objetivas de los fenómenos, cuantitativa y cualitativamente, y en cuanto nos referimos a las bases existenciales de los fenómenos en conjunto.

La imaginación posibilita, con su síntesis de lo múltiple intuitivo, que siempre es homogéneo, la unidad intuitiva; y más aún, la resistencia estructural que ofrece todo fenómeno en su materialidad sensible se debe también a la capacidad de sintetizar, pues la síntesis trascendental de la imaginación resume los modos de afección en una continua realidad, posibilitando la unidad cualitativa. Mas esta síntesis trae, según vemos, la indicación de cómo lo que se nos enfrenta es algo que dura, y si varía lo hace mediante determinaciones. Es la síntesis la que posibilita, en cierto modo, el supuesto unitario y fundamental de los hechos.

Poro la imaginación, como facultad activa por excelencia, no cesa de formar, construir y vincular, y no cesa tampoco de trabajar en favor de una experiencia unitaria. Así, el conjunto intuitivo sensorial, modificado en cierto modo y ordenado por las síntesis espontáneas y objetivas del espíritu, no por haber sido aprehendido como un todo deja de carecer de multiplicidad y aparecérsenos como una realidad inmóvil. Esta realidad se da en sus modificaciones (fenoménicas). La imaginación sintetiza las representaciones según su orden en el objeto, y posibilita la aplicación de la unidad de la determinación por la causa.

Pero, además, hay que considerar que los fenómenos se dan en conjunto y variando al mismo tiempo. La imaginación entonces se rige 
no por el ritmo con que se le presentan las representaciones de los diversos fenómenos, puesto que él es arbilrario, sino que guía su síntesis representativa conforme el objeto, haciendo posible una comunidad y afinidad entre los fenómenos.

El papel de la imaginación es trabajar, incesantemente, tanto por la unidad del fenómeno cuanto por la unidad de los fenómenos en conjunto (experiencia). Porque según Kant, sin la síntesis trascendental de la imaginación, podríamos hablar de funcionalismo unitario de los conceptos en general sin llegar a la consideración de un funcionalismo unitario de los objelos, y no objetivaríamos las representaciones con un contenido pleno.

Todo este proceso de la experiencia, si bien persigue la unidad, lleva dentro un sentido: el de referirse en último término a un dato intuitivo. Y la síntesis imaginativa, precisamente, trae el elemento intuitivo como alimento necesario a su función. Por eso, es sabido el papel ilustrativo y mostrativo de la imaginación, haciéndose factible la intuitividad a priori solamente por una exposición imaginativa.

Este mecanismo (si así puede llamársele) por forzado que se le considere, tiene dentro una sencillez significativa, la de expresar la participación de lo sensible en el conocimiento científico como apoyo primario.

Ahora que hemos penetrado más particularmente en las leyes científicas, podemos observar que la imaginación no es sólo un medio de unión entre lo sensible e inteligible (cosa que el Cesquema realizaría), sino una forma creadora y configuradora por excelencia. Lo demuestra: 1) en su juego analógico en favor de la homogeneidad (cantidad), 2) en su papel de integración al indicar cómo es posible que el conjunto sensorial presente la realidad como unidad opuesta al sujeto (cualidad), y 3) como facultad que propone o hace posible los supuestos imaginativos (sentido de ley del esquematismo en favor de la posibilidad de una intuición posible de toda ley conceptual), sustancia, causa, comunidad. Así, mirando de un modo general el campo científico y la imaginación en Kant, nos damos cuenta cómo ésta realiza ya un juego analógico, ya de integración, ya forjando supuestos objetivos.

Las inconmovibles leyes científicas que muestran esa rigidez racional, vistas desde esta perspectiva pierden un tanto su inconmovible apariencia, para enfrentarse como lineamientos que rigen todo el múltiple de objetos y de conocimientos, constituyendo en cierto modo respuestas que el juego incesante del espíritu se hace para encontrar la verdad y la unidad. 
$Y$ en esta interprełación creemos ver, más que una línea estrictamente racionalista, al explicar el hecho científico, algo asi como un asomo de lo irracional, factor que aparece oculto en la teoría kantiana, pero que, con ocasión de la imaginación y su sentido en la fundamentación de lo cientifico, se hace cada vez más insistente (25).

Por otra parte, si miramos desde el aspecto psicológico la participa ción de la imaginación en la Ciencia, podemos anotar su importancia, a pesar de que existió una época en que se negó su contribución en la elaboración del conocimiento científico.

La imaginación es primordial, psicológicamente considerada, en la estructuración lanto de las leyes científicas cuanto de los conceptos, los que a mayor generalidad llevan en si mayor significado. Algunas características de la imaginaçión cientifica, desde esto punto de vista, son indudablemente señaladas por Kant en la fundamentación de la ciencia.

\section{CAPITULO IV \\ HIPOTESIS, IMAGINACION Y METAFISICA \\ DOMINIO DE LA CIENCIA. EL LIMITE Y LAS LIMITACIONES}

La estructura del objeto, en un sentido amplio, se presenta como un aparecer a nosotros. y come algo que anuncia ese aparecer y lo respalda. El campo de la experiencia del que ienemos certeza, se circunscribe a lo fenoménico (apafecer del objeto). En este terreno ubicamos el hecho científico, que sólo es conocimiento válido de lo múltiple ferroménico.

Pero ante las citadas circunstancias, lo en sí (respaldo del aparecer) juega un papel fundamenial. En primer término, el impelu del sujeto pretende ampliar su órbila $e$ ir más allá del campo del aparecer, ensanchando el conocimiento hasia lo en sí, llegándose a la aseveración de que ésle hace relerencia a un contenido incondicionado aprehensible por conceptos. Mas tal opinión cae por su propia base, al hacerse patente que

(25) Aqui convienc transcribir una frase de Hujzinga que nos indicatía cn el sentido del juego, mutatis mutanelis. lo que distinguimos puede representar la inclusión de le imaginación en la lundamentación kantiana del conocimionto cientifico. "La exislencia del iuego corraborr constantemente. $Y$ en el seniclo más alto. el carácter supralóqico de nuestra situación on 6 l cosmos. Los animales puecien jugar y son, por lo tanto. algo más que cosas mecánjcas. Nosotros iugamos y suljomos que juganos; somos, por tarto, algo más que meros sares de razón. puesto gua el juego es irracional" ---LE juego y la cultura, por Hujzinga, cap. I. pág. 17). 
bajo la situación esbozada, de ningún modo se estruclura una experiencia. Como la negación del conocimiento de la cosa en sí es un hecho, se recurre entonces a la argumentación de la creación, por el poder inventivo del espíritu de un conienido congruente, presumiéndose alcanzar una especie de experiencia objetiva de lo absoluto.

Sin embargo, un análisis de las condiciones del conocimiento científico, nos sitúa nuevamente en el terreno de lo subjetivo, en donde jugamos con meras representaciones, puesto que la "experiencia objetiva" aquí consiste en un simple crear el objeto en forma arbitraria.

¿Queda acaso deshecha toda posibilidad de participación de lo en sí en el problema del conocimiento científico? ¿Qué papel puede jugar éste en la esfera epistemológica?, o al menos los conceptos racionales que apuntan a lo incondicionado ¿prestan algún aporte para el logro de la unidad?

En tanto encontremos que la cosa en sí y el supuesto de un factor incondicionado completan nuestro concepto unitario de las cosas y de su conjunto, podemos sin duda utilizar esa consideración. Dicho supuesto se admite, desde luego, en su carácter formal y director.

Si las categorías reglamentan la unidad de lo múltiple y los juicios que ellas posibilitan también estructuran esa unidad, no se debe dejar de considerar la intención de las fuerzas espirituales de llevarnos a una visión más general, para alcanzar una unidad completa que dé al objeto en toda su totalidad.

Las direcciones enumeradas, que a primera vista parecen antitéticas, encuentran su solución en un claro examen de los límites y las limitaciones, por el cual quedádaeterminado el papel de todos los conceptos y principios, y justificado el ímpetu del espíritu en su afán de conocimiento infinito.

En los límites y las limitaciones, se contempla nítidamente el panorama del campo epistemológico y los alcances del conocimiento teórico.

Si nos fijamos en lo que son los límites, distinguimos que ellos presuponen algo fuera de lo que encierran, lo cual sirve a su vez para encerrar lo dado como limitado. Las limitaciones, como Kant lo enuncia, son en cambio meras negaciones que afectan a una cantidad en tanto carezca de totalidad absoluta. La razón tiene la misión (dentro del campo del conocimiento de lo objetivamente válido) de proponer la existencia de una realidad suprafenoménica y, a su vez, señalarla -cosa en sí mismo. La razón, al anunciar esta zona y al saber que a ella es imposible penetrar por el conocimiento, está indicando los límites. Pues desde tal ángulo, apunta y aborda lo que en parte completa lo dado, pero a lo que es im- 
posible llegar. Mas, dicho trabajo de la razón, también proporciona la visión de que las ciencias son esferas en las cuales se labora dentro de limitaciones, es decir donde se actúa sobre fenómenos. Las limitaciones de ningún modo expresan que las conocimientos de las ciencias diversas tengan límites. Por el contrario, si cada ciencia trabaja sobre el terreno del fenómeno y si el fenómeno es una limitación, el conocimiento del propio fenómeno ofrece un infinito de posibilidades en el cual ya no hay límites. Kant, refiriéndose a las ciencias, hace notar que las ciencias reconocen la existencia de algo fuera de ellas a donde nunca se puede llegar, pero no que puedan ser acabadas en su proceso interno.

Si bien la razón nos conduce a los línites del conocimiento, a su vez encuentra su limitación en la experiencia, puesto que, si penetra en el conocimiento de lo general, ya no se circunscribe a lo válido sino que juega con representaciones a priori y conjuntamente con la fantasía; ya aquí no objetiva sino fantasea. Es decir, que si de la razón se hace un uso correcto, ella también encuentra su limitación.

Aquí descansa la justificación más interesante del significado de la razón: que si no llega a un conocimiento más allá de la experiencia, cumple, sin embargo, en el conocimiento y en la ciencia, un papel esencial, cual es el de dirigir la experiencia a una unidad (26).

Por eso, los conceptos de razón no son tomados como conceptos que nos llevan a un conocimiento fuera de la experiencia, sino que los conceptos racionales son directivas para que el campo de la experiencia se perfile desde un punto de vista unitario, mediante el supuesto de una condición máxima.

\section{LA HIPOTESIS Y EL CONOCIMIENTO CIENTIFICO}

A) La ciencia exige supuestos, que aunque en cierto modo elevan el conocimiento a lo inaccesible, al mismo tiempo le proponen motivos para una dirección cognoscitiva de carácter universal. En la consideración de los supuestos básicos de toda posición científica, aparece la hipótesis como arma necesaria.

Una jerarquía de supuestos hipotéticos verifica la unidad. El procedimiento de la unidad, según supuestos hipotéticos, se produce: 1) me-

(26) Kant lo explica cuando dice: "Pero, la limitación del campo de la experiencia por algo que a ella le es, en otro caso, desconocido, es, pues, un conocimiento que le está reservado a la razón desde este punto de vista, porque no se encierra dentro del mundo do los sentidos ni fantasea tampoco fuera de él, sino que, como conviene a un conocimiento de los límites, se restringe meramente a la relación de aquéllo que está dado fuera del mișmo con lo que está contenido dentro".--(Prolegómenos, N 59, pág. 184, trad. J. Besteiro). 
diante supuestos generales y puros de los diferentes objetos conocidos, 2) por supuestos de conceptos racionales y puros de todos los conocimientos de los objetos en conjunto, y 3) por el supuesto que da unidad a todo el conjunto de objetos y de conocimientos.

1) La unidad de los objelos se alcanza por la hipótesis de un concepto general y puro, que indica la dirección de todos los objetos que tengan la misma característica, y que necesiten apoyarse en uno general, como vía para su unidad objetiva (27).

Hay aquí una admisión implícita de un supuesto hipotético, que justifica la estructura unitaria de los objetos y sus modalidades. Pero estos supuestos, lo son de la particularidad objetiva, es decir de cada objeto; más los conjuntos de dichas particularidades en modo alguno son heterogéneos, porque entonces producirían una ruptura en la unidad de la ciencia, debiendo regirse a su vez por nuevos supuestos hipotéticos de mayor generalidad.

2) Hay en segundo lugar otros supuestos generales (y también puros), que abarcan el conjunto de los conocimientos de los diversos objetos para fundamentar la experiencia. Se supone así, en todos los conocimientos, la existencia de una homogeneidad de lo vario, homogeneidad visible en la actitud siempre manifiesta de buscar formas más generales que unifiquen lo plural. Además, también el conjunto de conocimientos supone la especificidad, pues lo homogéneo vinculado a lo particular tiende a ser en cada caso algo diferente. Mas en esta estructuración de la unidad por la búsqueda de lo general y de la pluralidad de lo general para ser particular; en la citada irterdependencia de supuestos (homogeneidad y especificidad), se encuentra otra suposición que es la de la Continuidad, ya que al pasar de uno a otro concepto (específico o general) siempre lo hacemos en forma continua y nunca produciéndose escisiones.

3) Por último, en la jerarquía de supuestos hipotéticos en favor de la unidad, llegamos a lo que propiamente es la idea máxima de la razón,

(27) "Se admite la dificultad de encontrar la tierra pura, el agua pura, el aire puro, etc. Se tiene concepto de estas cosas (las que, atendiendo a su perfecta pureza, no acusan su origen más que en la razón) a fin de determinar propiamente la parte que cada una de estas causas naturales tiene en los fenómenos; redúcense asi todas las materias a las tierras (de alguna manera al simple peso), a las sales y a las sustancias combustibles (como a la fuerza), al agua y al aire como a los vehículos (a las máquinas por medio de las cuales obran los elementos precedentes), a fin de explicar las acciones químicas de las materias entre sí según los fenómenos. Aún cuando, en efecto, no se expresa así esta influencia de la razón sobre las divisiones de los físicos, es sin embargo, muy fácil de percibir".-(Crítica de la razón pura, t. II, pág. 252, trad. M. Fernández Núñez). 
que implica la unidad de todo el conjunto (objetos y conocimientos de dichos objetos). Los conceptos de razón (ideas), son los que proyectan todos los conceptos del entendimiento hacia una unidad brindada por este concepto. $Y$ es que el conocimiento científico es un conocimiento de las partes y de ningún modo de la tctalidad, pues ésta precede a las partes. En consecuencia, suponer el todo es algo previo para abarcar el sentido y la amplitud de nuestros conocimientos.

B) Pero hasta aquí parece que llegáramoi a aquellas construcciones conceptuales, racionales e hipotéticas, creadas arvitrariamente. Si así se entendiera el anterior proceso, mal podría haber existido toda la problemática crítica. La participación de los conceptos racionales como hipotéticos, debe ser entendida desde esta actitud: la importancia de las hipótesis no consiste en representür merarnente una cuestión racional metodológica, sino en ser una explicación a la que están deierminados tanto los objetos cuanto el entendimiento que los conoce. Si el objeto y el entendimiento poseen el supuesto racional de una unidad máxima, la hipótesis no es simplemente una hipótesis ordenüdora, sino una hipótesis que brota de la estructura misma de los objetos que se nos oponen y del entendimiento que los conoce. Sólo entonces el objeto epistemológico y el sujeto que los conforma y capta, están determinados por un supuesto fundamental que los ensambla en una realidad racional, elevándolos a una uniformidad de rango superior.

Estos supuestos, desde luego, ya no son formas impuestas con el casi prejuicio de organizar, sino que afloran de las características mismas de los objetos y de las estructuras espirituales cognoscitivas.

La hipótesis cobra en la ciencia um profundo significado, al brotar como indiscutible elemento de la esencia del conocimiento, de la correlación de los elernentos que lo constituyen. Porque la unidad que presentan los conceptos del conocimierito no es meramente conceptual, sino que la poseen también los propios objetos, y porque se da la unidad correlativa entre el concepto y el objeto, es que podẹmos, aunque parezca paradógico, referirnos, en segundo término, a la unidad lógica. Quiere decir que no se parte de lo formal, para adaptarlo y encapsular a los objetos mediante una forma metodológica del conocimiento, sino que la unidad es un supuesto objetivo de los propios objetos del conocimiento, por lo cual esta unidad - según Kant- alcanza apodicticidad.

Así las hipótesis, aún saliendo del campo de la experiencia, colaboran en su propia unidad, constituyendo un sistema. Es obvia la utilidad de estas hipótesis, que a pesar de salir del campo de la experiencia son las que lo estructuran. 
El campo hipotético científico está determinado por condiciones. Las hipótesis sólo pueden darse como hip jtesis de fenómenos, porque su validez radica no en el apoyarse sobre otro supuesto, sino por el contrario en algo factible.

Por lo expuesto, hemos apreciads cómo penetra el significado de la hipótesis en el conocimiento mismo, al revelarse como un telos inmanente que no se impone como elemento ajeno, sino que emerge necesariamente del ser de lo conocido y de lo conocido mismo. En este sentido, y sólo en éste, se puede considerar la hipótesis como factor fundamental en la ciencia.

\section{EL SISTEMA EN EL CONOCIMIENTO}

Lo supuestos o hipótesis básicas para toda ciencia, llegan a vincular los conocimientos según una estructura, originando un sistema.

Si la hipótesis es un supuesto básico para proporcionar y completar la unidad, el sistema no es otra cosa que conocimientos diversos ensamblados bajo una idea (unidad). La idea subsume una totalidad, en donde se determina la situación de los elementos, $y$, en general, de todas las partes que le pertenecen. El todo, como conjunto orgánico, es un sistema.

La totalidad implica aún otras cualidades, pues el todo admite modificaciones internas, es decir admite mayor número de elementos, sin que salgan de la esfera total (per intussussceptionem), mas el todo no puede admitir otras formas que lo rebasen externamente, ya que ésta lo incluiría a su vez como elemento (per oppositionem).

La idea hace el papel de punto de referencia, que organiza la unidad cognoscitiva y de ningún modo nos proyecta a un conocimiento de lo absoluto.

La idea para desarrollarse plenamente recurre a la necesidad de formas medianeras, que en la ciencia son el orden de los elementos, dirigidos y determinados antes de toda experiencia (a priori) según una finalidad. El sistema en una ciencia es determinado a propósito de una idea, con un fin previo. Por eso, la ciencia puede guardar su peculiar validez y erigir principios, que hacen de su dominio un conjunto regido por leyes.

Debemos añadir que, a través del pensamiento de Kant, se trasluce el deseo de perseguir un sistema Y, más aún, se palpa que toda su investigación encierra esa finalidad arquitectural. De allí que se haya sugerido que su teoría es un tanto forzada, hecha a propósito con ideas prefijadas. Sin embargo, podríamos agregar, que si bien existe una tendencia al sistema, aquí se pretende, a diferencia de los demás, cimentar uno sobre bases sólidas. 
La investigación de Kant, en último término, remata en un sistema. A su vez cada investigación parcial conforma un sistema especial, que tiene profunda conexión y enlace con otros, para en último término dar lugar a un sistema total, el cual nos manifiesta la actitud integralista de este filósofo frente a todos los hechos culturales.

\section{IA FANTASIA}

Una modalidad de la imaginación, en cuanto sale del campo de la experiencia, constituye la Fantasía. En ella se pueden distinguir dos fases: 1) la fantasía como colaboradora en la objetividad, 2) la fantasía como ejemplaridad subjetiva.

En primer lugar, los supuestos objetivos (hipótesis) son formas que la imaginación (fantasía) llena de realidad, imprimiéndoles, debido a su poder intuitivo, mayor fuerza y evidencia. En este sentido, la fantasía participa en la labor de objetivación; reune y crea a base de lo dado, y sólo engendra una intuición para justificar algo factible.

En segundo lugar, la fantasía realiza una labor plenamente subjetiva, fuera de toda legislación, en sentido predominantemente creador. Esta labor la verifica más allá de los cánones científicos. Si la capacidad de unificar y llegar a lo incondicionado lleva al espíritu a sentirse capacitado para un conocimiento de lo absoluto, encuentra en la fantasía un apoyo al generar un objeto afín por medio de la elaboración de una materialidad sin condiciones.

La imaginación lleva dentro un empuje que la impulsa a rebasar, por decirlo así, los límites de la experiencia, y a engendrar representaciones en su propia existencia. Del mismo modo que el espíritu persigue la unidad máxima, la imaginación pretende forjar un objeto adecuado.

Pero la capacidad de espontaneidad y unidad y el poder inventivo de la fantasía, nos ponen en contacto con realidades desde todo punto de vista subjetivas (28). Es entonces cuando la fantasía crea hipótesis sobre hipótesis, y no encuentra en esta forma ningún sólido apoyo.

"Para que la imaginación no sueñe, sino que pueda imaginar bajo la estrecha vigilancia de la razón, es preciso que se apoye antes sobre algo perfectamente cierto y que no sea imaginario

(28) "Entonces se eleva, (el entendimiento) primeramente, a nuevas fuerzas inventadas de la naturaleza, poco después a seres fuera de ella, en una palabra, a un mundo para cuya construcción no nos puede faltar materia, porque es espléndidamente procurada por la invención fecunda $y$. si no ha de ser nunca confirmada por la experiencia, tampoco ha de ser refutada".--(Prolegómonos, No 35, pág. 108. trad. J. Besteíro). 
o de simple opinión, y este algo es la posibilidad del objeto mismo".- - Crítica de la razón pura, t. II, pág. 331, trad. M. Fernández Núñez).

En esta doble interpretación de la fantasía y, en consecuencia, de la imaginación en general, colaborando en la objetividad y como forma subjetiva, cabe anotar la clara dilucidación kantiana sobre dicha facultad. Porque la imaginación siempre había sido considerada como mera fantasía y no bajo una amplia perspectiva.

Es necesario reconocer el juego de la imaginación en sus dos aspectos, como ya lo han expresado algunos investigadores, al considerar que actúa en lo real y en lo posible.

\section{IMAGINACION, LO IRRACIONAL Y LO METAFISICO}

Hemos intentado descifrar el significado de la imaginación en la teoría kantiana del conocimiento, y desentrañar qué representa su inclusión, qué problemas encierra y a cuáles conduce.

A través del estudio realizado, vimos cómo la imaginación (trascendental a priori) al colaborar en el conocimiento científico, tiene las mismas características señaladas en la moderna concepción psicológica sobre esta facultad. Y en el terreno epistemológico, es índice de una posible extensión de la espontaneidad a lo irracional y reafirmación de los puntos básicos (unidad sintética y contenido intuitivo) en todo conocimiento científico.

En este sentido representaría el desmoronamiento del criticado punto de vista racionalista " $y$, al mismo tiempo, una superación de su propia teoría.

Pero las anteriores soluciones nos remiten al estudio de dos nuevos problemas en la filosofía de Kant: el de lo irracional y el de lo metafísico.

\section{1}

Creemos que el análisis del primer problema, nos llevaría a distinguir dos facetas de lo irracional: una, impuesta por el propio sujeto mediante una facultad no racional (imaginación); otra, como término al que se llega cuando se hace imposible una racionalización, que se ciña a los puntos de vista de todo conocimiento válido.

Lo irracional, emergiendo del propio sujeto, llevaría a una fundamentación más amplia de todo conocimiento científico y psicológico (aunque el problema de Kant fué sólo la fundamentación del conocimien- 
to científico), por haber considerado en lo sensible cierta autonomía y validez (síntesis aprehensiva como efecto de la imaginación). Y además, la imaginación como f́acultad no racional y a la vez configuradora, más allá del terreno científico, en el estético por ejemplo, puede representar un indicio para ampliar la experiencia.

Consideramos en Kant ampliación de la experiencia, no sólo el intento de fundamentar otros campos aparte del científico (estético, ético), sino el hacer participar en la fundamentación de todos ellos, formas opuestas a las intelectuales, no racionales, y que a pesar de ello organizan, codifican (especie de formas categoriales autónomas).

La participación de la imaginación como fuente no racional y su constancia en diferentes esferas de objetivación ¿podría ser sospecha que lo racional y lo no racional son formas necesarias?

Por otra parte, lo irracional como término al que se apunta en los límites mismos de la ciencia ¿no indicaría la existencia de otros problemas, y la línea a seguirse en sus interpretaciones? La persistencia de zonas no racionales en todas las esferas experimentales ¿no nos llevaría a consideraciones que responden a problemas ya de índole metafísica y que deben enfocarse como restos no solucionados de aquellas esferas?

Y no queremos dejar pasar por alto, la importancia que tiene el problema de lo irracional. Sabido es cómo este problema ha preocupado profundamente a los pensadores.

Modernamente ha cobrado una gran importancia el problema de lo irracional, tanto en el aspecto de lo emocional cuanto en el aspecto de lo teórico.

El racionalismo si bien pudo haberle concedido a lo emocional algún papel, lo hizo asimilándolo a lo racional. Actualmente lo irracional emocional ha conquistado su autonomía, siendo opuesto a lo racional, pero tan válido y preciso como él.

Lo irracional, desde lo teórico, ha sido tratado históricamente. Los neokantianos, a pesar de su idealismo, no dejan de admitir en cierto modo un irracional, ya no como frontera a la cual la razón es absolutamente impenetrable, sino como signo de la existencia de algo que continuadamente nosotros persistimos en racionalizar pero que es inabordable (29).

(29) Natorp señala su diferencia con el hegelianismo, el cual afirma que lo irracional, si existe, en último término, puede ser asimilado por lo racional.-(Eın. Kant y la escuela filosófica de Marburgo). 
En nuestros días el problema de lo irracional en sentido estricto, se refiere conjuntamente tanto a lo irracional no lógico cuanto a lo racional cognoscible y es anuncio de problemas ontológicos, por la presencia de cuestiones irresolubles a las cuales de continuo nos acercamos.

Se ha llegado a la consideración de lo auténticamente irracional, que emerge de las aporías mismas de la ciencia y de la vida, y que es aigno de la existencia de algo que lo trasciende, desembocándose de este modo en una ontología. Este tema así considerado, nos pone en los linderos de toda una concepción acerca del ser.

Ciertos puntos oscuros de la teoría de Kant (la imaginación por ejemplo), comúnmente descuidados o superficialmente solucionados, pueden ser los gérmenes de lo que posteriormente constituyeron los nuevos puntos de vista. El estudio de la imaginación muestra gran afinidad con el problema de lo irracional, y puede servir para enfocar la filosofía crítica desde un plano más amplio.

\section{2}

Una de las interroganles que con gran insistencia abre el estudio del significado posible de la imaginación, es la relacionada con cuestiones de orden metafísico. La imaginación parece presentar innumerables rastros, para indicar los elementos metafísicos en la teoría crítica. Aunque pudiese ser contradictorio llegar a tales afirmaciones, creemos que éste es uno de los problemas que tienen mayor fuerza en una interpretación no unilateral ni racionalista.

Es verdad que la existencia del problema de la metafísica ha sido frecuentemente discutido. Los neokantianos rechazan todo vuelo metafísico e indican como primordial y exclusiva la Teoría del Conocimiento. Sin embargo, en la revalorización de la teoría kantiana, se hace notorio cómo debido a constantes interrogaciones metafísicas y a las por entonces existentes especulaciones sobre el ser, se yergue la actitud crítica. Ella, a pesar de su carácter epistemológico, deja entrever serias y penetrantes resistencias metafísicas. Son fuerzas de otra naturaleza las que surgen en los límites del conocimiento, en la posición ética y en la teleología.

Más aún, es el sujeto, y su espontaneidad, quien delinea un nuevo enfoque de aquellos problemas; y de ningún modo el ímpetu de las fuerzas espirituales y la limitación del conocimiento, nos pone fuera del planteamiento de temas metafísicos, sino por el contrario es la única vía que puede realmente conducirnos a ellos. 
En el estudio realizado (que sólo abarca lo referente a la ciencia), vimos cómo la imaginación representaba un afán de reunión, de síntesis, pero al mismo tiempo nos hicirnos conscientes de su limilación al dato intuitivo.

Considerando grosso modo este asunto, convendría averiguar: si la ciencia utiliza la unidad objetiva y la ley, y para que se verifiquen ambas es necesario una síntesis ¿qué representaría la síntesis como efecto de la imaginación, facultad no intelectual?, ¿cómo pueden apoyarse la unidad objetiva y la ley en un poder que no sea genuinamente racional?

Si el objeto, en el conocimiento, implica una limitación a lo intuitivo sensible $\mathrm{y}$, precisamente, la imaginación es la que suministra a priori el dato intuitivo, ¿cómo se justifica que ella cree formas arbitrariamente, rebasando todos los límites del conocimiento, siempre de manera sensible?, ¿qué representaría ser una fuerza de creación y empuje inventivos y a la vez de limitación?

Insistimos en que una nueva revisión de algunos temas, efectuada con mayor serenidad, puede hacer visible perspectivas audaces que Kant ya había entrevisto.

\section{NELLY FESTINI ILLICH.}

\section{B I B L I O G R A F I A}

BASCH, Vicor: L' imagination dans la théorie kantienne de la connaissance. -Revue de Métaphysique et de Morale.-1904.-Pág. 425.

BESTEIRO, Julián: Los juicios sintéticos a priori desde el punto de vista lógico.-Ediciones La Lectura.-Madrid. 1922.

CASSIRER, Ernst: Filosofía de la ilustración.-Fondo de Cultura Económica.-México.-1943.

CASSIRER, Ernst: Epílogo (Cuatro temas kantianos, insertos en los Prolegómenos). Editorial Daniel Jorro.-Madrid.-1912.

DESCARTES, Renato: Discurso del Método.-Editorial Sopena.-Buenos Aires.-1942.

DILTHEY, Guillermo: La esencia de la Filosofía.-Editorial Losada.-Buenos Aires.-1944.

DUGAS, L.: La imaginación.-Editorial Jorro.-Madrid.-1901.

DWELSHAUVERS, J.: Tratado de Psicología.-Editor Gustavo Gili.--Barcelona.-1930. 
HANNEQUIN, Arthur: Les principes de $l^{\prime}$ entendement pur, leur fondement, leur importance, dans la Critique de la Raison Pure.-Revue de Métaphysique et de Morale.-1904.-Pág. 401.

HARTMANN, Nicolai: El pensamiento filosófico y su historia.-Editores Claudio García y Compañía.-Montevideo.-1944.

HEIDEGGER, Martín: ¿Qué es Metatísica?-Editorial Séneca.-México.1941 .

HEIDEGGER, Martín: Esencia del fundamento.-Editorial Séneca.-México.-1944.

HEIMSOETH, Heinz: La Metafísica Mcderna.-Revista de Occidente.Madrid.-1932.

HUME, David: Investigación sobre el entendimiento humano.-Editorial Losada.-Buenos Aires.-1939.

HUSSERL, Edmundo: Investigaciones Lógicas.-Revista de Occidente.Madrid.-1929.

HUSSERL, Edmundo: Meditaciones Cartesianas._Colegio de México.1942.

KANT, Manuel: Crítica de la Razón Pura. (Trad. M. Morente).-Lib. Victoriano Suárez.-Madrid.-1928.

KANT, Manuel: Crítica de la Razón Pura. (Trad. Fernández Núñez).-Imp. Zaez Hnos.-Madrid.=1934.

KANT, Manuel: Prolegómenos.-Editorial Daniel Jorro.-Madrid.-1912. KANT, Manuel: Trałado de Lógica.-Editorial Araujo.-Busnos Aires. 1938. KANT, Manuel: Antropología.-Revista de Occidenie.-Madrid.-1935. KANT, Manuel: Crítica del Juicio.-Lib Victoriano Suárez.-Madrid.1914.

KANT, Manuel: Crítica de la Razón Práctica.-Biblioteca Clásica Universal.-Madrid.-1939.

KANT, Manuel: Lo Bello y lo Sublime--Barcelona.-1919.

KLEMM, Otto: Historia de la Psicología.-Editorial D. Jorro.-Madrid.1919.

KULPE, O.: Kant.--Colección Labor.-Buenos Aires.-1939.

NATORP, P.: Em. Kant, y la escuela filosófica de Marburgo.-Editor Francisco Beltrán.-Madrid.-1915.

NEUSCHLOSZ, S. M.: Análisis del conocimiento científico.-Editorial Losada.-Buenos Aires.-1939.

POINCARE, Henri: La ciencia y la hipótesis.-Espasa-Calpe.-Argentina. $-1943$.

RENOUVIER, Charles: Los dilemas de la metafísica pura.-Editorial Losada.-Buenos Aires.-1944. 
RIBOT, Th.: La imaginación creadora.-Lib. V. Suárez,-Madrid.-1901. RUSSELL, Bertrand: El A, B, C. de la relatividad.-Ediciones Imán.-Buenos Aires.-1943.

SCHELER, Max:-Etica. Nuevo ensayo de fundamentación de un personalismo ético.-Rev. de Occidente.-Madrid.-1941.

SCHELER, Max.: El puesto del hombre en el cosmos.-Rev. de Occtdente.-Madrid.-1936.

SCHELER, Max: El saber y la cultura.-Editorial Cultura.-Santiago de Chile.-1937.

WHITEHEAD, Altred N.: Modos de pensamiento.-Editorial Losada.-Buenos Aires.-1944.
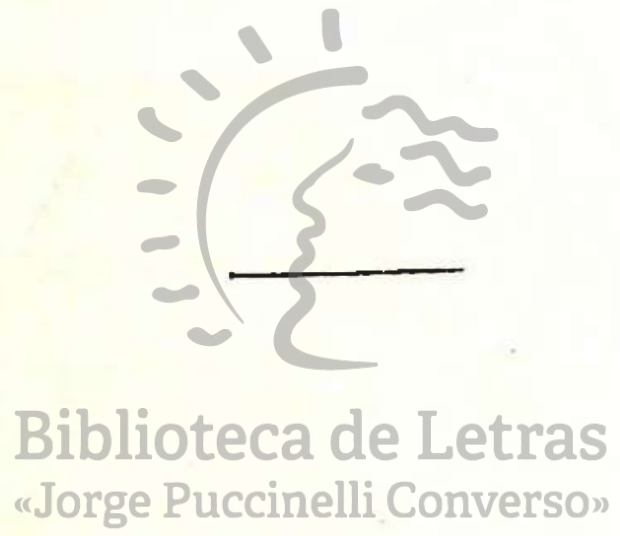